\title{
Adsorption Isotherm, Kinetic and Thermodynamic Modelling of Bacillus subtilis ATCC13952 Mediated Adsorption of Arsenic in Groundwaters of Selected Gold Mining Communities in the Wassa West Municipality of the Western Region of Ghana
}

\author{
Emmanuel Agyapong Asare ${ }^{*}$, Emmanuel Dartey ${ }^{1}$, Kofi Sarpong1, Emmanuel Effah-Yeboah ${ }^{2}$, \\ Papa Kofi Amissah-Reynolds², Sheila Tagoe ${ }^{3}$, Gadafi Iddrisu Balali ${ }^{4}$
}

\footnotetext{
${ }^{1}$ Department of Chemistry Education, College of Agriculture Education, Akenten Appiah-Menka University of Skills Training and Entrepreneurial Development, Mampong-Ashanti, Ghana

${ }^{2}$ Department of Biological Sciences Education, College of Agriculture Education, Akenten Appiah-Menka University of Skills Training and Entrepreneurial Development, Mampong-Ashanti, Ghana

${ }^{3}$ Department of Molecular Biology, School of Biological Sciences, College of Agriculture and Natural Sciences, University of Cape Coast, Cape Coast, Ghana

${ }^{4}$ Department of Theoretical and Applied Biology, Kwame Nkrumah University of Science and Technology, Kumasi, Ghana Email: *kwakuasareagyapong@yahoo.com
}

How to cite this paper: Asare, E.A., Dartey, E., Sarpong, K., Effah-Yeboah, E., Amissah-Reynolds, P.K., Tagoe, S. and Balali, G.I. (2021) Adsorption Isotherm, Kinetic and Thermodynamic Modelling of Bacillus subtilis ATCC13952 Mediated Adsorption of Arsenic in Groundwaters of Selected Gold Mining Communities in the Wassa West Municipality of the Western Region of Ghana. American Journal of Analytical Chemistry, 12, 121-161.

https://doi.org/10.4236/ajac.2021.125010

Received: February 22, 2021

Accepted: May 18, 2021

Published: May 21, 2021

\begin{abstract}
This study investigated Bacillus subtilis ATCC13952 as an adsorbent for arsenic in groundwater. Batch experiments were used to determine the effect of contact time, adsorbent dose, arsenic (III) concentration, $\mathrm{pH}$, and temperature on the process. The percentage of arsenic (III) removed was high at a contact time of four days, $3.0 \mathrm{~mL}$ of Bacillus subtilis ATCC13952, $\mathrm{pH} 8$ and temperature of $35^{\circ} \mathrm{C}$. The kinetics of the process showed the Elovich kinetics model as the best fit for the process. This indicates that arsenic removal was by chemisorption. The analysis of the nonlinear equilibrium isotherms and the error functions showed the Langmuir isotherm as best fit for the process. Mechanistic study of the process indicated bulk diffusion to be the ratedetermining step. Thermodynamically, the process was favourable, spontaneous and feasible. When the community water samples were treated with the Bacillus subtilis ATCC13952 at the optimum contact time, adsorbent dose, $\mathrm{pH}$ and temperature, 99.96\% - 99.97\% of arsenic was removed across all sampling points within the studied communities. Hence, the results show that
\end{abstract}


Copyright $\odot 2021$ by author(s) and Scientific Research Publishing Inc. This work is licensed under the Creative Commons Attribution International License (CC BY 4.0).

http://creativecommons.org/licenses/by/4.0/
Bacillus subtilis ATCC13952 is an efficient adsorbent for arsenic in aqueous systems and the organism appears to hold the key to purging the environment of arsenic contamination.

\section{Keywords}

Adsorption Isotherms, Bacillus subtilis ATCC13952, Kinetic, Thermodynamic, Nonlinear Error Functions, Sum of the Normalized Errors, Chemisorption

\section{Introduction}

Though water is a vital component for human development and a cross-cutting element in Ghana's developmental efforts to achieve sustainable growth, a significant number of water bodies in Ghana has become severely polluted in recent times owing to illegal gold mining on river beds [1] [2]. The situation is worrying as several surface water resources have become coloured and silted, thus making them unusable [3]. Hence, mining communities are in constant need of potable water and rely on groundwater resources for their water needs [4]. However, danger looms as several studies conducted on groundwater quality in gold mining communities in Ghana have reported substantial levels of arsenic often exceeding the $10 \mu \mathrm{g} / \mathrm{L}$ permitted by the WHO [5] [6]. Arsenic in drinking water has been reported to cause human diverse health problems, including cancer, skin thickening and discolouration, high blood pressure, heart diseases, nerve effects like numbness and pain, interference with important cell functions, gastrointestinal disorders, diarrhea, stomatitis, tremor, hemoglobinuria, ataxia, paralysis, depression, pneumonia, among others [5] [7] [8]. Although technologies such as lime precipitation, oxidation, coagulation filtration, ion exchange and reverse osmosis have been developed and refined to remove arsenic from water, such technologies are expensive and the poverty-stricken mining communities cannot afford them. For this reason, no efforts have been made to remove the metalloid from groundwater resources of these communities and inhabitants consume arsenic-contaminated water. Hence, it is imperative that groundwater resources in these mining communities are improved to prevent morbidity and mortality resulting from the consumption of groundwater with high arsenic levels of the resources preserve the lives of inhabitants.

This study used Bacillus subtilis ATCC13952 isolated from soil samples of a gold mining site in the Wassa West District of the Western Region of Ghana to develop novel, affordable, efficient, and ecologically friendly technique to remove arsenic that has intruded and contaminated groundwater sources in selected mining communities in the district. To achieve this, the background levels of arsenic in groundwater of the communities were determined. The removal capacity of the Bacillus subtilis ATCC13952 was optimized through simulated laboratory trials on prepared arsenic (III) solution. The data obtained was sub- 
jected to selected adsorption isotherms and kinetic models to determine mechanism(s) used by the Bacillus subtilis ATCC13952 to remove the arsenic. Thermodynamic properties of the process were done to assess the feasibility of integrating the organism into a continuous flow water treatment facility to remove arsenic. Finally, the developed method was applied on groundwater samples to ascertain the possibility of its application in large-scale community water treatment.

\subsection{Materials and Method}

Chemicals and reagents used were of analytical quality and were supplied by $\mathrm{BDH}$ chemical limited (United Kingdom). The chemicals and reagents used include 36\% AnalaR hydrochloric acid, 70\% AnalaR nitric acid, sodium arsenite and iodine tenture. The bacillus subtilis strain ATCC13952 (adsorbent) was obtained from the Department of Molecular Biology, University of Cape Coast, Ghana. The arsenic removal method developed involved optimization of physicochemical parameters via the batch adsorption technique. The idea was to determine the factors that would allow maximum removal of arsenic by the Bacillus subtilis ATCC13952 (adsorbent). The parameters investigated were contact time, amount of the adsorbent, arsenic concentration, $\mathrm{pH}$ and temperature.

\subsection{Effect of Contact Time on Arsenic Removal}

The effect of contact time was investigated by altering the contact time whilst the other physicochemical factors viz: the amount of the Bacillus subtilis ATCC13952, arsenic (III) concentration, $\mathrm{pH}$ and temperature were kept constant. Hundred millilitres of $10 \mathrm{mg} / \mathrm{L}$ arsenic (III) in the form of sodium arsenite solution were transferred into $250 \mathrm{~mL}$ Erlenmeyer flasks labelled $1-7$ days. One millilitre of the adsorbent was added to the contents of each flask. The flasks were tightly sealed with cotton wool plugs wrapped with aluminium foil to create an airtight reactor. They were then fitted onto a flask shaker (Model IKA ${ }^{(\mathrm{R})}$ KS 260 Basic) and operated at $250 \mathrm{rpm}$. At 24-hour interval, a flask was taken and 3 drops of iodine solution added. It was swirled vigorously to ensure thorough mixing and then allowed to stand for 20 minutes. This was done to ensure that the iodine quenches the action of the bacteria before samples were analysed for the residual arsenic. The contents of the flasks were centrifuged at $3700 \mathrm{rpm}$ for 5 minutes to separate the bacteria from the treated arsenic (III) solution with an $801 \mathrm{D}$ electric centrifuge. The resultant supernant solutions were filtered into $250 \mathrm{~mL}$ flat bottom flasks and then subjected to vigorous digestion by aqua regia for residual arsenic (III) analysis.

\subsubsection{Effect of Amount of Adsorbent on Arsenic Removal}

The amount of Bacillus subtilis ATCC13952 required for maximum arsenic removal was investigated by varying the amount of the bacteria whereas the remaining factors viz contact time, arsenic (III) concentration, $\mathrm{pH}$ and temperature were kept constant. Hundred millilitres of $10 \mathrm{mg} / \mathrm{L}$ arsenic (III) solutions 
were transferred into six separate $250 \mathrm{~mL}$ Erlenmeyer flasks. These volumes 1.5, 2.0, 2.5, 3.0, 3.5 and $4.0 \mathrm{~mL}$ of the Bacillus subtilis ATCC13952 were added to the contents of each flask. The flasks were tightly sealed with cotton wool plugs wrapped with aluminium foil to create an air tight reactor. They were fitted onto a flask shaker and operated at $250 \mathrm{rpm}$ for four days identified as the period required for maximum arsenic removal from the contact time investigation. At the end of the $4^{\text {th }}$ day, 3 drops of iodine solution were added to the contents of each flask, swirled vigorously and allowed to stand for 20 minutes. This was done to ensure that the Bacillus subtilis ATCC13952 action was quenched before treated samples were digested for residual arsenic analysis. To separate the arsenic loaded bacteria from the treated arsenic (III) solutions, the contents of the flasks were centrifuged at $3700 \mathrm{rpm}$ for 5 minutes. The resultant supernatant solutions were transferred into $250 \mathrm{~mL}$ flat bottom flasks and digested with aqua regia. The residual concentration of the arsenic (III) solution was analysed using Inductively Coupled Plasma Optical Emission Spectroscopy.

\subsubsection{Effect of Arsenic Concentration on Removal Capacity of B. subtilis ATCC13952}

The effect of arsenic on the arsenic removal capacity of the Bacillus subtilis ATCC13952 was studied by varying arsenic (III) concentration whilst the contact the time, the amounts of the Bacillus subtilis ATCC13952, $\mathrm{pH}$ and temperature were maintained. Hundred millilitres aliquots of $20,40,60,80$ and 100 $\mathrm{mg} / \mathrm{L}$ of arsenic (III) solution were transferred into five separate $250 \mathrm{~mL}$ Erlenmeyer flasks. Three millilitres of the bacteria were added to each flask. The flasks were tightly sealed with cotton wool plugs wrapped with aluminium foil to create an air tight reactor. The flasks were then put on a flask shaker and operated at $250 \mathrm{rpm}$ for the four days determined to be required for maximum removal of arsenic. On the $4^{\text {th }}$ day, 3 drops of iodine solution were added to the contents of each flask and were swirled vigorously to mix their contents. The flasks were allowed to stand for 20 minutes to ensure that the Bacillus subtilis ATCC13952 action is quenched. The bacteria were moved from the treated arsenic (III) solution by centrifuging with $801 \mathrm{D}$ electric centrifuge at $3700 \mathrm{rpm}$ for 5 minutes. The resulting supernant solutions were transferred into five $250 \mathrm{~mL}$ flat bottom flasks and digested with aqua regia for the residual arsenic (III) analysis.

\subsubsection{Effect of pH on Arsenic Removal Capacity of Bacillus subtilis ATCC13952}

This was investigated by varying the $\mathrm{pH}$ of the arsenic (III) solution whilst keeping constant the amount of the Bacillus subtilis ATCC13952, the contact time, the temperature and the arsenic (III) concentration. Hundred millilitres of $80 \mathrm{mg} / \mathrm{L}$ arsenic (III) solution was transferred into each of five of the $250 \mathrm{~mL}$ Erlenmeyer flasks labelled with $\mathrm{pH}$ values of $2,4,6,8$ and 10 . The $\mathrm{pH}$ of the arsenic (III) solution in the flasks labelled with $\mathrm{pH}$ values of 2, 4 and 6 were adjusted from its natural $\mathrm{pH} 7.05$ to $\mathrm{pH}$ of 2,4 and 6 respectively by dropwise addition of 
$0.2 \mathrm{M}$ aqueous solution of $\mathrm{HCl}$ whilst the $\mathrm{pH}$ values of 8 and 10 were adjusted respectively by dropwise addition of an $0.2 \mathrm{M}$ aqueous solution of $\mathrm{NaOH}$. Three millilitres of the Bacillus subtilis ATCC13952 were added to the contents of each flask. The flasks were tightly sealed with cotton wool plugs wrapped with aluminium foil to create airtight reactors. The flasks were then shaken at $250 \mathrm{rpm}$ for four days. At the end of the period, 3 drops of iodine solution were added to the contents of each flask. The flasks were then swirled vigorously to mix the contents and allowed to stand for 20 minutes. This was done to ensure that the bacteria action was terminated by the iodine. The contents of the flasks were centrifuged at $3700 \mathrm{rpm}$ for 5 minutes to remove the bacteria. The resulting supernant solutions were each transferred into five $250 \mathrm{~mL}$ flat bottom flasks and digested with aqua regia for residual arsenic (III) analysis.

\subsubsection{Effect of Temperature on Arsenic Removal Capacity of Bacillus subtilis ATCC13952}

The optimum temperature required to achieve maximum arsenic removal was investigated by keeping constant the contact time, the amount of the Bacillus subtilis ATCC13952, the $\mathrm{pH}$, and the concentration of the arsenic (III) solution whilst varying the temperature. Hundred millilitres of $80 \mathrm{mg} / \mathrm{L}$ arsenic (III) solution were transferred into five $250 \mathrm{~mL}$ Erlenmeyer flasks labelled with temperature of $29^{\circ} \mathrm{C}, 34^{\circ} \mathrm{C}, 39^{\circ} \mathrm{C}, 44^{\circ} \mathrm{C}$ and $49^{\circ} \mathrm{C}$. Three millilitres of the Bacillus subtilis ATCC13952 were added to the content of each flask. The flasks were tightly sealed with cotton wool plugs wrapped with aluminium foil to create air tight reactors. The flasks and their contents were placed in a five capacity heating mantle and the temperatures were set at $29^{\circ} \mathrm{C}, 34^{\circ} \mathrm{C}, 39^{\circ} \mathrm{C}, 44^{\circ} \mathrm{C}$ and $49^{\circ} \mathrm{C}$ and monitored for four days. At the end of the $4^{\text {th }}$ day, 3 drops of iodine solution were added to the content of each flask. The flasks were swirled to mix the contents, and allowed to stand for 20 minutes. This was to ensure that the bacteria action was quenched. The contents of the flasks were centrifuged at $3700 \mathrm{rpm}$ for 5 minutes to separate the bacteria from the aqueous phase. The resulting supernant solutions were transferred into $250 \mathrm{~mL}$ Erlenmeyer flasks and digested with aqua regia. The residual arsenic (III) was determined by ICPOES. For each of the physic-chemical factors investigated, $1 \mu \mathrm{L}$ of the resulted supernant solution was pipetted and cultured onto a fresh nutrient agar media and monitored for four days. This was done to ensure that the Bacillus subtilis ATCC13952 action was completely quenched before samples were digested for residual arsenic (III) and mercury (II) determination. The optimization process was repeated thrice to determine the reproducibility of the process.

\subsubsection{Digestion of Treated Arsenic Solution for Residual Arsenic Determination}

Following the optimization, $100 \mathrm{~mL}$ of arsenic (III) solution treated with the $\mathrm{Ba}$ cillus subtilis ATCC13952 for each of the five physico-chemical parameters investigated were transferred into $250 \mathrm{~mL}$ flat bottom flasks. Fifty millilitres of aqua regia were added to the contents of each flask. The flasks were swirled 
gently to ensure proper mixing. They were then placed on a hot plate and the contents digested at $95^{\circ} \mathrm{C}$. Complete digestion occurred when the volumes of the arsenic (III) solution being digested were reduced approximately to $10 \%$ of the initial volume with the disappearance of the brown nitrogen dioxide gas produced. The digested samples were allowed to cool to room temperature and then transferred into $100 \mathrm{~mL}$ graduated flasks. The flasks used for the digestion were rinsed twice each with $5 \mathrm{~mL}$ of diluted water and then added to the corresponding contents of the $100 \mathrm{~mL}$ flasks. The volumes of the resulted solutions in the $100 \mathrm{~mL}$ flasks were adjusted to the mark with distilled water. The residual arsenic (III) was determined using Inductively Coupled Plasma Optical Emission Spectroscopy.

\subsubsection{Community Water Samples Collection}

Groundwater samples were collected from Ackon, Tamso and Odumasi in the Wassa West District of the Western Region of Ghana. In Ackon and Tamso, water samples were collected from two hand dug wells and a borehole. In Odumasi, water samples were collected from two hand dug wells, a borehole and surface water. A total of twenty samples were collected into previously acid washed high density plastic bottles. The hand dug wells were sampled with a high density plastic bucket with a long rope attached to the opened end. The bucket was then lowered into the well, allowed to get filled with water and then pulled up. The content of the bucket was poured back into the well. The procedure was repeated four times to ensure that the contents of the well were thoroughly mixed before samples were collected. The groundwater samples were then collected into the high density plastic bottles, sealed tightly and then properly labelled. Prior to borehole water sampling, water was pumped out of the borehole supply system for a minute to ensure that water samples were collected from significant depth. Water was then pumped into the previously washed high density plastic bottles, sealed tightly and then properly labelled. For the surface water sampling, four spots that had fast moving water that could be reached from the bank of the water body were selected. Sampling was done at depth of 15 - $20 \mathrm{~cm}$. The labelled bottles with their covers were placed flat on their sides under the water. The mouths of the submerged bottles were then pointed upstream and the covers were then removed under water to allow water to fill the bottles. After sampling, bottles covers were replaced and sealed tightly. The samples were transported to the laboratory for analysis of the levels of arsenic.

\subsubsection{Digestion of Water Samples for Background Arsenic Determination}

Hundred millilitres of the groundwater samples were put into $250 \mathrm{~mL}$ flat bottom flasks. Fifty millilitres of aqua regia were added and mixed thoroughly, placed on a hot plate at $95^{\circ} \mathrm{C}$ for digestion. Complete digestion occurred when the volumes of the samples being digested had reduced by approximately $90 \%$ with no emission of the brown nitrogen dioxide gas. The samples digested were 
removed from the hot plate and allowed to cool to room temperature. The digests were transferred into $100 \mathrm{~mL}$ flasks. The flasks used for the digestion were rinsed twice each with $5 \mathrm{~mL}$ of diluted water and then added to the respective contents of the $100 \mathrm{~mL}$ flasks. The volumes of the resulted solutions in the 100 $\mathrm{mL}$ flasks were adjusted to the mark with distilled water for the determination of the background arsenic levels of the groundwater.

\subsubsection{Blank Samples Preparation for Arsenic Determination}

To prepare sample blanks, $100 \mathrm{~mL}$ of distilled water was put into $250 \mathrm{~mL}$ flat bottom flasks. Fifty millilitres of aqua regia were added. The mixture was mixed thoroughly and placed on a hot plate at $120^{\circ} \mathrm{C}$ for digestion. Complete digestion occurred when the emission of brown nitrogen dioxide gas disappeared. The samples were transferred into $100 \mathrm{~mL}$ flasks and the volumes were adjusted to the mark with distilled water. Both the digested groundwater and the blanks were analysed using inductively coupled plasma optical emission spectroscopy.

\subsubsection{Groundwater Samples Treatment for Residual Arsenic Analysis Using Bacillus subtilis ATCC13952}

Hundred millilitres of the groundwater samples were put into $250 \mathrm{~mL}$ flat bottom flasks. The $\mathrm{pH}$ of the samples was adjusted to 8 by dropwise addition of 0.2 M sodium hydroxide. Three millilitres of the Bacillus subtilis ATCC13952 were then added. The flasks were then swirled gently to ensure uniform distribution of the bacteria. The flasks were tightly sealed with cotton wool plugs wrapped with aluminium foil to create air tight reactors to avoid contamination. The flasks with contents were placed on a heating mantle at $34^{\circ} \mathrm{C}$ for four days. At the end of the $4^{\text {th }}$ day, 3 drops of iodine solution were added to the contents of the flask while warm. The flasks were swirled gently and allowed to stand for 20 minutes. The flasks with contents were centrifuged at $3700 \mathrm{rpm}$ for 5 minutes to separate the bacteria from the aqueous phase. The resulted supernatant solutions were transferred into $250 \mathrm{~mL}$ flat bottom flasks. Fifty millilitres of aqua regia were added and mixed thoroughly. The contents of the flasks were then digested on a hot plate at $95^{\circ} \mathrm{C}$. The digested groundwater samples were removed from heating, allowed to cool to room temperature, and then transferred into $100 \mathrm{~mL}$ flasks. The flasks were rinsed twice each with $5 \mathrm{~mL}$ of distilled water and added to the respective contents in the $100 \mathrm{~mL}$ flasks. The contents of the $100 \mathrm{~mL}$ flasks were adjusted to the mark with distilled water. The processes were repeated thrice to determine the reproducibility of the method. The contact time of four days, the $\mathrm{pH}$ of 8 , the Bacillus subtilis ATCC13952 amount of $3.0 \mathrm{~mL}$ and the temperature of $35^{\circ} \mathrm{C}$ used for sample treatments were the most suitable conditions that will afford a favourable removal of arsenic (III) as observed in the simulation experiments conducted on the prepared arsenic (III) solution. To ensure that the Bacillus subtilis ATCC13952 action was quenched completely, $1 \mu \mathrm{L}$ each of the resulted solutions were pipetted after centrifuging and cultured onto nutrient agar media. They were observed for four days to check the effectiveness of the iodine to kill the bacteria. 


\subsection{Isotherm Modeling of the Adsorption Data}

The design and effective functioning of an adsorption process generates adsorption data for use in the kinetic, thermodynamic, and mass transfer models of adsorption [9]. Adsorption isotherms relate the amount of adsorbate adsorbed onto the adsorbent and the residual amount of the adsorbate in the aqueous phase when the adsorption process has attained equilibrium [10]. The isotherms are mathematical equations having parameters which are vital in the design and functioning of an adsorption system [9]. The values of isotherm parameters give information about the surface properties of an adsorbent, its affinity for the adsorbate and are vital in optimizing the use of the adsorbent [11].

In this study, the amount of arsenic (III) adsorbed onto Bacillus subtilis ATCC13952 was studied using seven different nonlinear adsorption isotherm equations. These were Langmuir, Freundlich, Temkin, Toth, Dubinin-Radushkevich, Sips, and the Redlich-Peterson isotherms. Although linear forms of the isotherms have been used in describing adsorption systems [12] [13], the non linear forms were used in this study. This was because the adsorption isotherms were developed in view of certain assumptions [10]. Therefore, linearizing them would undermine the assumptions upon which they were developed and can result in a flawed outcome [14]. Linearization of isotherms has been applied in several studies to determine the fit of an isotherm to an adsorption data because its interpretation is simple [12] [13]. The linear forms of the isotherms use the coefficient of determination $\left(R^{2}\right)$ to predict the fit of the isotherm to the experimental data [14]. The isotherm with $R^{2}$ close to unity is selected as the isotherm which better explains the adsorption process [15]. The non-linear form of the isotherms although extremely complex offers a remarkable and precise mathematical approach to determining the isotherm parameters [10]. Thus, the isotherm parameters in this study were determined using the non-linear approach to avoid inaccuracies that would originate from linearization [16].

\subsubsection{The Langmuir Isotherm}

The Langmuir isotherm assumes monolayer coverage of adsorbate on a homogeneous surface where the adsorption sites are identical and energetically equivalent. Adsorption occurs at specific localized sites on the surface of the adsorbent. Each site can accommodate one metal ion and there is no interaction between adjoining ions adsorbed [17]. There exists a saturation point where no further adsorption could occur because the adsorption sites have been occupied by the adsorbate [10]. Therefore, the adsorbent has a finite ability for the metal ions. The Langmuir isotherm is represented by the equation:

$$
Q_{e}=Q_{m} b C_{e} / 1+b C_{e}
$$

where $b(\mathrm{~L} / \mathrm{mg})$ is the Langmuir isotherm constant which denotes the metal ion binding affinity constant, $Q_{e}(\mathrm{mg} / \mathrm{g})$ and $C_{e}(\mathrm{mg} / \mathrm{L})$ are equilibrium solid and liquid phase concentrations of the adsorbate respectively and $Q_{m}(\mathrm{mg} / \mathrm{g})$, the maximum amount of metal ions adsorbed per unit mass or volume of the ad- 
sorbent. An essential dimensionless parameter $\left(R_{L}\right)$, a characteristic of the Langmuir isotherm is expressed as:

$$
R_{L}=1 / 1+K_{L} C_{o}
$$

The $R_{L}$ is a separation factor and it determines whether the adsorption process is favourable or unfavourable [18]. The adsorption process is unfavourable when the separation factor $R_{L}$ is greater than unity $\left(R_{L}>1\right)$, linear when the separation factor $R_{L}$ is equal to unity $\left(R_{L}=1\right)$, favourable when the separation factor $R_{L}$ lies in the range $0<R_{L}<1$. When the separation factor $R_{L}$ is equal to zero $\left(R_{L}=0\right)$, the adsorption progress is irreversible [19].

\subsubsection{The Freundlich Isotherm}

The Freundlich isotherm is an empirical mathematical equation used to describe multilayer adsorption processes. The isotherm explains that the amount of the adsorbate adsorbed by a given mass or volume of an adsorbent would increase with an increase in the concentration of the adsorbate in solution [10]. This isotherm is applied to adsorption onto heterogeneous surfaces [20]. The isotherm equation is expressed as:

$$
Q_{e}=K_{f} C_{e}^{1 / n}
$$

where $K_{f}(\mathrm{~L} / \mathrm{mg})$ is the Freundlich isotherm constant which is related to adsorption capacity, $C_{e}(\mathrm{mg} / \mathrm{L})$ which is the residual aqueous phase concentration of the adsorbate and $1 / n$ is the heterogeneity factor. The heterogeneity factor lies between 0 and 1 and is related to the adsorption intensity and gives information on the nature of the adsorption process.

\subsubsection{The Temkin Isotherm}

The Temkin isotherm examines adsorbate-adsorbate interactions in the adsorption process. The Temkin isotherm assumes that the adsorption surface is characterized by uniform distribution of binding energies and the heat of adsorption decreases linearly with an increase in the surface coverage of the adsorbent as a result of the adsorbate-adsorbate interactions [21]. The Temkin isotherm equation is expressed as:

$$
Q_{e}=\left(R T / b_{\tau}\right) \ln \left(K_{\tau} C_{e}\right)
$$

where $b_{\tau}$ is related to the heat of adsorption $(\mathrm{kJ} / \mathrm{mol}), R$ is the gas constant $(8.314$ $\left.\mathrm{J} \cdot \mathrm{mol}^{-1} \cdot \mathrm{K}^{-1}\right), T$ is the absolute temperature $(K)$ and $K_{\tau}$ is the Temkin constant $(\mathrm{L} / \mathrm{g})$ which corresponds to the maximum binding energy.

\subsubsection{The Toth Isotherm}

The Toth isotherm is a three parameter isotherm which is useful in describing the behaviour of adsorption on a heterogeneous surface [22]. The isotherm is able to explain the behaviour of heterogeneous surface adsorption of low and high concentration boundaries of a given adsorbate [22]. The Toth isotherm is expressed as:

$$
Q_{e}=Q_{t} K_{t} C_{e} /\left(1+K_{t} C_{e}\right)^{1 / t}
$$


where $Q_{t}$ is the Toth maximum adsorption capacity, $K_{t}$ is the Toth isotherm constant and $1 / t$ is the Toth exponent. When $t$ approaches unity, the isotherm reduces to the Langmuir isotherm equation [23]. Toth isotherm assumes asymmetrical Quasi-Gaussian energy distribution with a widened left side to indicate that most of the adsorption sites of an adsorbent have energy less than the mean adsorption energy [24].

\subsubsection{The Dubinin-Radushkevich Isotherm}

Though the Dubinin-Radushkevich isotherm does not explain adsorption on homogeneous or heterogeneous surface nor assumes constant adsorption energy, its application is to differentiate physical and chemical adsorption processes [25]. The isotherm equation is expressed as:

$$
Q_{e}=Q_{\max } \exp \left(-B_{D}\left[R T \ln \left(1+1 / C_{e}\right)^{2}\right]\right)
$$

where $Q_{\max }(\mathrm{mg} / \mathrm{g})$ is the Dubinin-Radushkevich monolayer capacity, $T(\mathrm{~K})$ is temperature of the solution. The constant $B_{D}$ is related to the mean adsorption energy by equation:

$$
E=1 / \sqrt{2} B_{D}
$$

The mean adsorption energy is the energy change when one mole of the ions is transferred from an infinite distance in solution to the surface of the adsorbent [25]. The value of the mean adsorption energy provides insight into the nature of the adsorption mechanism. The adsorption mechanism is considered to be chemical in nature when the magnitude of the mean adsorption energy ranges between $8-16 \mathrm{~kJ} / \mathrm{mol}$ [26]. When the magnitude of the mean adsorption energy lies between $1-8 \mathrm{~kJ} / \mathrm{mol}$, the adsorption mechanism is considered to be physical in nature [26].

\subsubsection{The Sips Isotherm}

The Sips isotherm eliminates the limiting deficiencies associated with the Langmuir and the Freundlich isotherms by merging them into a single equation [27]. At low adsorbate concentration, the Sips isotherm equation is reduced to the Freundlich isotherm [28]. At high adsorbate concentration, the Sips isotherm predict monolayer adsorption capacity characteristic of the Langmuir isotherm equation [29]. The Sips isotherm equation is expressed as:

$$
Q_{e}=\left(Q_{s} K_{s} C_{e}^{1 / n}\right) /\left(1+K_{s} C_{e}^{1 / n}\right)
$$

where $Q_{s}(\mathrm{mg} / \mathrm{g})$ is the Sips maximum adsorption capacity, $K_{s}(\mathrm{~L} / \mathrm{g})$ is the Sips constant, and $1 / n$ is the Sips exponent.

\subsubsection{The Redlich-Peterson Isotherm}

The Redlich-Peterson is a three parameter empirical equation used to explain adsorption processes over wide range of concentrations [29]. The isotherm combines features of Langmuir and Freundlich equations and therefore could be used to explain both heterogeneous and homogenous adsorption systems [27]. The isotherm equation is expressed as: 


$$
Q_{e}=K_{R p} C e /\left(1+A_{R} C_{e}^{\beta}\right)
$$

where $K_{R}(\mathrm{~L} / \mathrm{g})$ and $A_{R}(\mathrm{~L} / \mathrm{mg})$ are Redlich-Peterson adsorption and affinity constants respectively. The constant $\beta$ ranges between 0 and 1 and its represent Redlich-Peterson exponent.

\subsubsection{Nonlinear Error Functions Analysis}

Though non-linear approach to error assessment is complex and sophisticated, it restrains errors which would have occurred through linearization of the nonlinear error [30]. The fit of the selected isotherms to the experimental adsorption data were evaluated through optimization of the selected error functions. Ten nonlinear error functions viz: Sum of the Squares of the Errors (ERRSQ), Residual Root Mean Square Error (RMSE), Chi Square $\left(\chi^{2}\right)$, Log-likelihood ratio $\left(\mathrm{G}^{2}\right)$, Sum of the Absolute Errors (EABS), Average Percentage Error (APE), Composite Fractional Error Function (HYBRID), Marquand's Percent Standard Deviation (MPSD) and Average Relative Error (ARE) were analyzed to determine the isotherm(s) that better elucidate the experimental data [31]. The parameters of the selected isotherms were determined by minimizing the selected error functions associated with the isotherm parameters estimation using the solver add-in programme of Microsoft 2007 excel spread sheet [32]. The errors were determined by assigning initial arbitral numerical constants to the isotherm parameters and then applying the constants to write a single excel readable mathematical programme for both the selected isotherms and the errors by incooperating the residual amount of arsenic (III) in the aqueous phase and the amount removed by the Bacillus subtilis ATCC13952 as reported [32] [33]. The excel readable mathematical programme was automated using the generalized reduced gradient algorithm of the solver add-in programme to determine the actual values of the selected errors and the parameters of the isotherms. The resulting values of the errors were normalized and combined into a sum of the normalized standard errors to select the isotherm that best fit the adsorption process [32].

\subsubsection{Sum of the Squares of the Errors}

The sum of the squares of the errors (ERRSQ) is expressed as:

$$
\sum_{i=1}^{N}\left(q_{\mathrm{e}, \exp }-q_{\mathrm{e}, \mathrm{calc}}\right)_{i}^{2}
$$

where $q_{e, \text { exp }}$ is the experimentally determined amount of the adsorbate removed by the adsorbent and $q_{e, \text { cal }}$ is the theoretically determined amount of the adsorbate removed by the adsorbent and was estimated using the selected isotherm equations [34]. Though application of sum of the squares of the errors is widespread, for high residual amount of the adsorbate, the magnitude of this error increase and therefore this error gives a better fit for the isotherm parameters at high residual concentration of the adsorbate when the error function is minimized [34] [32]. 


\subsection{Average Relative Error}

The absolute value of the average relative error (ARE) was used in the determination of the isotherm parameters [35]. The absolute value of this error minimizes the spread of the error distribution across the concentration range applied in an adsorption process [36]. The Average relative error equation is expressed as:

$$
\sum_{i=1}^{N}\left|\frac{q_{\mathrm{e}, \mathrm{exp}}-q_{\mathrm{e}, \mathrm{calc}}}{q_{\mathrm{e}, \mathrm{exp}}}\right|_{i}
$$

\subsubsection{Sum of the Absolute Errors}

The absolute value of the sum of the absolute errors (EABS) was applied in the determination of the isotherm parameters [33]. The sum of the absolute errors approach is similar to the sum of the squares of the errors function [35]. The isotherm parameters determined through this error tend to present a better fit towards high concentration adsorption data [37]. The equation is expressed as:

$$
\sum_{i=1}^{N}\left|q_{\mathrm{e}, \exp }-q_{\mathrm{e}, \text { alc }}\right|_{i}
$$

\subsubsection{Chi Square}

The chi square $\left(\chi^{2}\right)$ statistical test procedure establishes how well an isotherm equation best approximate an experimental adsorption system [38]. The chi square statistic is expressed by the equation:

$$
\chi^{2}=\sum_{i=1}^{N} \frac{\left(q_{\mathrm{e}, \mathrm{exp}}-q_{\mathrm{e}, \text { calc }}\right)^{2}}{q_{\mathrm{e}, \text { calc }}}
$$

The isotherm equation that in theory approximates the experimental adsorption system better would have a smaller chi square value [38].

\subsubsection{The Hybrid Fractional Error Function}

The hybrid fractional error function (HYBRID) is composite fractional error which was developed to improve the fit of the sum of the squares of the errors at low residual concentration of the adsorbate [39]. The hybrid fractional error function is expressed as:

$$
\sum_{i=1}^{N}\left[\frac{\left(q_{\mathrm{e}, \exp }-q_{\mathrm{e}, \mathrm{calc}}\right)^{2}}{q_{\mathrm{e}, \mathrm{exp}}}\right]_{i}
$$

\subsubsection{Residual Root Mean Square Error}

The residual root mean square error (RMSE) was applied to determine the goodness of fit of the selected isotherm models to the experimental data. Smaller residual roots mean square error values are indicative of better curve fitting [40]. The equation is given by the expression:

$$
\sqrt{\frac{1}{n-2} \sum_{i=1}^{N}\left(q_{\mathrm{e}, \exp }-q_{\mathrm{e}, \mathrm{cal}}\right)^{2}}
$$




\subsubsection{The Log-Likelihood Ratio}

The log-likelihood ratio $\left(G^{2}\right)$ statistic was determined by using Equation (16) [41]. When the concentration of adsorbate experimentally determined $q_{\mathrm{e}}$ exceeds that of the theoretical $q_{\mathrm{m}}$, the ratio $\ln \left(q_{\text {exp }} / q_{\mathrm{m}}\right)$ is positive. Conversely, when the concentration of adsorbate theoretically determined $q_{\mathrm{m}}$ exceeds that of the experimental $q_{\mathrm{e}}$, the ratio $\ln \left(q_{\text {exp }} / q_{\mathrm{m}}\right)$ is negative [42].

$$
G^{2}=2 \sum_{i}^{N}\left[q_{\mathrm{exp}, i} \times \ln \left(\frac{q_{\mathrm{exp}, i}}{q_{\mathrm{m}, i}}\right)\right]
$$

The log-likelihood ratio becomes better when a large difference exists between the experimental and theoretical values [43]. Under a null hypothesis, the experimentally determined log-likelihood ratio distribution is approximated to the log-likelihood ratio distribution determined theoretically [44]. Therefore, the probability of obtaining the log-likelihood ratio statistical value could be determined from chi-square distribution [41].

\subsubsection{The Average Percentage Error}

The average percentage error (APE) was used to determine the accuracy of the selected isotherm equation in the theoretical prediction of the experimental data [45]. The average percentage error is expressed by Equation (17) as:

$$
\frac{\sum_{i=1}^{n}\left|\left(q_{\mathrm{e}, \exp }-q_{\mathrm{e}, \text { calc }}\right) / q_{\mathrm{e}, \exp }\right|_{i}}{N} \times 100
$$

\subsubsection{Marquand's Percent Standard Deviation}

The Marquand's percent standard deviation (MPSD) was used to determine the number of degrees of freedom of the adsorption system [14]. The Marquand's percent standard deviation function is expressed by Equation (18) as:

$$
\sum_{i=1}^{N}\left[\frac{\left(q_{\mathrm{e}, \exp }-q_{\mathrm{e}, \text { calc }}\right)}{q_{\mathrm{e}, \exp }}\right]_{i}^{2}
$$

\subsubsection{Sum of the Normalized Standard Errors}

The sum of the normalized standard error functions (SNSE) was applied as a criterion to select the isotherm equation that best fitted the experimental adsorption process and data [46]. The sum of the normalized standard errors was determined by using the following procedure: 1) an isotherm equation and standard error functions were selected. 2) The isotherm parameters that would minimize the selected standard error associated with the selected isotherm were determined. 3) The values of the standard error of the selected isotherm and the isotherm parameters were determined. 4) The values of the error determined were divided by the largest error value among the selected standard errors of the selected isotherms to obtain the normalized standard error. 5) The normalized standard errors of the selected isotherms were added. 6) The isotherm equation that yielded the minimum value of the sum of the normalized standard errors was selected as the isotherm which best fitted the adsorption process and the 
data [10] [46].

\section{Results and Discussion}

The rationale for the optimization process was to determine conditions of contact time, amount of the Bacillus subtilis ATCC13952, the concentration of arsenic (III) solution, the $\mathrm{pH}$ and the temperature that would give optimum removal of arsenic [47]. Three separate laboratory Experiments (I, II and III) were conducted on laboratory simulated arsenic (III) contaminated aqueous system using the Bacillus subtilis ATCC13952 as biosorbent for the arsenic.

The contact time optimization (Table 1) showed a significant decrease in the initial amount of the arsenic (III) from $10-9.26 \mathrm{mg} / \mathrm{L}, 10-9.40 \mathrm{mg} / \mathrm{L}$ and $10-$ $9.33 \mathrm{mg} / \mathrm{L}$ as seen in Experiment I, II and III respectively, when $100 \mathrm{~mL}$ of 10 $\mathrm{mg} / \mathrm{L}$ arsenic (III) solution was contacted with 1.0 of the Bacillus subtilis ATCC13952 on the first day. When contact time was increased to the second day, the initial concentration of arsenic decreased from $10-4.22 \mathrm{mg} / \mathrm{L}, 10-4.30$ $\mathrm{mg} / \mathrm{L}$ and $10-4.02 \mathrm{mg} / \mathrm{L}$ as indicated in Experiment I, II and III respectively for the same amount of the Bacillus subtilis ATCC13952. A further increase of contact time beyond the fourth day (Table 1) resulted in a significant decrease in the initial concentration of the arsenic (III). The Bacillus subtilis ATCC13952 exhibited high ability to remove arsenic on the fourth day.

The proportion of arsenic (III) removed in the contact time optimization increased rapidly from $7.32 \%-97.02 \%, 6.00 \%-96.97 \%$ and $6.68 \%-96.88 \%$ as seen in Experiment I, II and III respectively from the first to the fourth day. Across the experiments, the largest amount of arsenic was removed on the fourth day (Table 2). The percentage of the arsenic (III) removed from first to the fourth day could mean that the Bacillus subtilis ATCC13952 might have large number of unsaturated active adsorption sites on the surface and took four days for the arsenic (III) to saturate these active sites. Possible saturation of the adsorption sites by arsenic (III) might have caused the reduction seen in the ability of the Bacillus subtilis ATCC13952 to a removed substantial amount of arsenic.

Table 1. Result of contact time optimization for arsenic (III) adsorption.

\begin{tabular}{ccccccc}
\hline \multirow{2}{*}{$\begin{array}{c}\text { Contact } \\
\text { Time(Days) }\end{array}$} & \multicolumn{2}{c}{ Experiment I } & \multicolumn{2}{c}{ Experiment II } & \multicolumn{2}{c}{ Experiment III } \\
\cline { 2 - 6 } 1 & $C_{e}$ & $Q_{e}$ & $C_{e}$ & $Q_{e}$ & $C_{e}$ & $Q_{e}$ \\
\hline 2 & 9.2674 & 0.7326 & 9.4014 & 0.6006 & 9.3316 & 0.6684 \\
3 & 4.2207 & 5.7293 & 4.3071 & 5.6939 & 4.0241 & 5.9759 \\
4 & 2.4338 & 7.5662 & 2.2584 & 7.4756 & 2.7023 & 7.2977 \\
5 & 0.2979 & 9.7021 & 0.3046 & 9.6974 & 0.3114 & 9.6886 \\
6 & 1.1668 & 8.8332 & 1.3016 & 8.6984 & 1.3147 & 8.6853 \\
7 & 1.2844 & 8.7156 & 1.3043 & 8.6957 & 1.3324 & 8.6676 \\
\hline
\end{tabular}


Table 2. Percentage of arsenic (III) adsorbed in time optimization.

\begin{tabular}{cccc}
\hline \multirow{2}{*}{ Contact time (Days) } & Experiment I & Experiment II & Experiment III \\
\cline { 2 - 4 } & \% Removed & \% Removed & \% Removed \\
\hline 1 & 7.326 & 6.006 & 6.684 \\
2 & 57.293 & 56.939 & 59.759 \\
3 & 75.662 & 74.756 & 72.977 \\
4 & 97.021 & 96.974 & 96.886 \\
5 & 88.332 & 86.984 & 86.853 \\
6 & 87.156 & 86.957 & 86.676 \\
7 & 87.007 & 86.399 & 85.999 \\
\hline
\end{tabular}

The results (Table 3) show amount of arsenic (III) removed in the Bacillus subtilis ATCC13952 optimization process. When the amount of the Bacillus subtilis ATCC13952 was increased from $1.5-3.0 \mathrm{~mL}$, the residual concentration of arsenic (III) decreased from $8.31-0.11 \mathrm{mg} / \mathrm{L}$ as in experiment I, $8.29-0.14$ $\mathrm{mg} / \mathrm{L}$ as seen in Experiment II and $8.29-0.12 \mathrm{mg} / \mathrm{L}$ as seen in Experiment III. Further increase in the amount of the Bacillus subtilis ATCC13952 from 3.0 - 4.0 $\mathrm{mL}$ resulted in a marginal increase in the residual arsenic (III) from 0.11- 0.58 $\mathrm{mg} / \mathrm{L}$ as seen in Experiment I, $0.14-0.59 \mathrm{mg} / \mathrm{L}$ as seen in Experiment II and 0.12 - $0.60 \mathrm{mg} / \mathrm{L}$ as seen in Experiment III. The lowest residual arsenic (III) of 0.11 $\mathrm{mg} / \mathrm{L}$ in Experiment I, $0.14 \mathrm{mg} / \mathrm{L}$ in Experiment II and $0.12 \mathrm{mg} / \mathrm{L}$ in Experiment III occurred when $3.0 \mathrm{~mL}$ of the Bacillus subtilis ATCC13952 was used. The arsenic (III) removal trend might have resulted from the availability of active adsorption sites on the surface of the Bacillus subtilis ATCC13952. It appears easier for arsenic (III) to be attached to the Bacillus subtilis ATCC13952 for removal. The decrease arsenic (III) removal ability of the Bacillus subtilis ATCC13952 when its quantity had been increased from $3.0-4.0 \mathrm{~mL}$ might have been due to the overlapping of the active adsorption sites as a result of overcrowding of the cells of Bacillus subtilis ATCC13952 making it difficult for the arsenic (III) to access the adsorptive sites.

The percentage of arsenic (III) removed (Table 4) increased from $16.85 \%$ 98.86\% as seen in Experiment I, $17.00 \%-98.58 \%$ as seen in Experiment II and $17.05 \%-98.77 \%$ as seen in Experiment III when the amount of the Bacillus subtilis ATCC13952 was increased from $1.5-3.0 \mathrm{~mL}$.

The high percentage removal of $98.86 \%$ as seen in Experiment I, $98.58 \%$ as seen in Experiment II and $98.77 \%$ as seen in Experiment III occurred with 3.0 $\mathrm{mL}$ of the Bacillus subtilis ATCC13952. Thereafter, further increase in the amount of the Bacillus subtilis ATCC13952 did not produce any increase in the percentage of arsenic (III) removed. Hence, $3.0 \mathrm{~mL}\left(2.83 \times 10^{-18} \mathrm{~g}\right)$ of the Bacillus subtilis ATCC13952 appeared to be the optimum amount required to achieve optimum removal of arsenic (III). The arsenic removal trend exhibited by the 
Bacillus subtilis ATCC13952 might be due to fact that the Bacillus subtilis ATCC13952 might have limited active adsorption sites and as its amount increased, the sites overlapped making it difficult for significant number of the arsenic to accessible the active adsorption, get attached to, and be removed.

As arsenic (III) concentration was increased from $20-80 \mathrm{mg} / \mathrm{L}$ (Table 5), the amount removed by $3.0 \mathrm{~mL}$ of the Bacillus subtilis ATCC13952 increased from 3.80 - $36.52 \mathrm{mg} / \mathrm{L}$ as seen in Experiment I, 3.77 - $36.28 \mathrm{mg} / \mathrm{L}$ as seen in Experiment II and $3.53-37.01 \mathrm{mg} / \mathrm{L}$ as seen in Experiment III. When the concentration of arsenic (III) was further increased from $80-100 \mathrm{mg} / \mathrm{L}$, the amount removed by $3.0 \mathrm{~mL}$ of the Bacillus subtilis ATCC13952 increased marginally from 36.52 - $36.84 \mathrm{mg} / \mathrm{L}$ as seen in Experiment I and $36.28-37.00 \mathrm{mg} / \mathrm{L}$ as seen in Experiment II. The removal trend indicates that when the initial concentration of arsenic (III) was increased from 80.0 - $100 \mathrm{mg} / \mathrm{L}$, the amount removed remained practically constant. This implies that the capacity of the Bacillus subtilis ATCC13952 to remove arsenic appears to be linearly dependent on arsenic (III) concentration of $20-80 \mathrm{mg} / \mathrm{L}$. The Bacillus subtilis ATCC13952 exhibited a high reproducibility in the amount of arsenic (III) removed as showed in the experiments. This shows that the organism could be used as a biosorbent for arsenic remediation.

Table 3. Bacillus subtilis ATCC13952 amount optimization for arsenic (III) removal.

\begin{tabular}{ccccccc}
\hline $\begin{array}{c}\text { Bacillus subtilis } \\
\text { ATCC13952 }\end{array}$ & \multicolumn{2}{c}{ Experiment I } & \multicolumn{2}{c}{ Experiment II } & \multicolumn{2}{c}{ Experiment III } \\
\cline { 2 - 7 } amount $(\mathrm{mL})$ & $C_{e}$ & $Q_{e}$ & $C_{e}$ & $Q_{e}$ & $C_{e}$ & $Q_{e}$ \\
\hline 1.5 & 8.3148 & 1.6852 & 8.2994 & 1.7006 & 8.2942 & 1.7058 \\
2.0 & 6.7036 & 3.2964 & 6.9246 & 3.0754 & 7.0102 & 2.9898 \\
2.5 & 2.1024 & 7.8976 & 2.3113 & 7.6887 & 2.4436 & 7.5564 \\
3.0 & 0.1137 & 9.8863 & 0.1416 & 9.8584 & 0.1201 & 9.8779 \\
3.5 & 0.5967 & 9.4033 & 0.6164 & 9.3836 & 0.5898 & 9.4102 \\
4.0 & 0.5876 & 9.4124 & 0.5997 & 9.4003 & 0.6014 & 9.3986
\end{tabular}

Table 4. Percent of As (III) adsorbed in B. subtilis ATCC13952 optimization.

\begin{tabular}{cccc}
\hline $\begin{array}{c}\text { Bacillus subtilis } \\
\text { ATCC13952 amount }\end{array}$ & Experiment I & Experiment II & Experiment III \\
\cline { 2 - 4 }$(\mathrm{mL})$ & \% Removed & \% Removed & \% Removed \\
\hline 1.5 & 16.852 & 17.006 & 17.058 \\
2.0 & 32.964 & 30.754 & 29.898 \\
2.5 & 78.976 & 76.887 & 75.564 \\
3.0 & 98.863 & 98.584 & 98.779 \\
3.5 & 94.033 & 93.836 & 94.102 \\
4.0 & 94.124 & 94.003 & 93.986 \\
\hline
\end{tabular}


Table 5. Result of arsenic (III) effect on removal capacity of Bacillus subtilis ATCC13952.

\begin{tabular}{|c|c|c|c|c|c|c|}
\hline \multirow{2}{*}{$\begin{array}{l}\operatorname{arsenic}(\mathrm{III}) \\
\text { conc. }(\mathrm{mg} / \mathrm{L})\end{array}$} & \multicolumn{2}{|c|}{ Experiment I } & \multicolumn{2}{|c|}{ Experiment II } & \multicolumn{2}{|c|}{ Experiment III } \\
\hline & $C_{e}$ & $Q_{e}$ & $C_{e}$ & $Q_{e}$ & $C_{e}$ & $Q_{e}$ \\
\hline 20.0 & 16.1934 & 3.8066 & 16.2261 & 3.7739 & 16.4628 & 3.5372 \\
\hline 40.0 & 24.4023 & 15.5977 & 25.4660 & 14.5340 & 25.5037 & 14.4963 \\
\hline 60.0 & 24.6164 & 35.3836 & 24.8421 & 35.1579 & 25.1394 & 34.8606 \\
\hline 80.0 & 43.4743 & 36.5257 & 43.7106 & 36.2894 & 42.9805 & 37.0195 \\
\hline 100.0 & 63.1504 & 36.8496 & 62.9964 & 37.0036 & 63.2201 & 36.7799 \\
\hline
\end{tabular}

An increased accessibility to the active adsorption sites on the Bacillus subtilis ATCC13952 by arsenic (III) in the initial stage of removal might explain the increased amount of arsenic (III) removed. The reduction in the quantity of arsenic removed after the initial concentration of arsenic (III) had been increased from $80-100.0 \mathrm{mg} / \mathrm{L}$ might have resulted due to saturation of the active adsorption sites on Bacillus subtilis ATCC13952. The percentage of arsenic (III) removed (Table 6) increased from $19.03 \%-58.97 \%$ as seen in Experiment I, $18.86 \%$ - 58.59\% as seen in Experiment II and 17.68\% - 58.10\% as seen in Experiment III when the initial concentration of arsenic (III) was increased from $20.0-60.0$ $\mathrm{mg} / \mathrm{L}$. When the arsenic (III) was further increase beyond $60.0 \mathrm{mg} / \mathrm{L}$ (Experiments I, II and III), no higher amounts were removed. The reduction in the capacity of the Bacillus subtilis ATCC13952 to removed significant quantity of arsenic beyond $60.0 \mathrm{mg} / \mathrm{L}$ of initial arsenic (III) concentration might have resulted from unavailability of active adsorption sites required for maximum removal due to surface saturation of the Bacillus subtilis ATCC13952. The amount of arsenic (III) removed from the laboratory simulations (Experiments I, II and III) were comparable and it reaffirms the reproducibility of the Bacillus subtilis ATCC13952 as biosorbent for arsenic in arsenic contaminated aqueous system.

The results of the effect of $\mathrm{pH}$ on arsenic (III) removal by the Bacillus subtilis ATCC13952 at varying $\mathrm{pH}$ from 2 - 10 (Table 7) show that the removal process increased gradually with $\mathrm{pH}$. The quantity of arsenic (III) removed increased from 5.00 - 9.84 mg/L as seen in Experiment I, 4.97 - $9.79 \mathrm{mg} / \mathrm{L}$ as seen in Experiment II and $5.10-9.76 \mathrm{mg} /$ Las seen in Experiment III when $\mathrm{pH}$ was varied from $2-8$. Further increase in $\mathrm{pH}$ from $8-10$ resulted in a decrease in the amount of arsenic (III) removed from $9.84-9.33 \mathrm{mg} / \mathrm{L}$ as seen in Experiment I, 9.79 - $9.29 \mathrm{mg} / \mathrm{Las}$ seen in Experiment II and 9.76 - $9.32 \mathrm{mg} / \mathrm{L}$ as seen in Experiment III. The maximum amounts of arsenic (III) removed in each of the experiments were similar and occurred at $\mathrm{pH} 8$. Hence, $\mathrm{pH} 8$ appeared to be the optimum $\mathrm{pH}$ to achieve best removal of arsenic (III).

The observed increase in the quantity of arsenic (III) at the optimum $\mathrm{pH}$ might have resulted from a decrease in competition between protons and the positively charged arsenic (III) in solution for attachment to the active adsorption sites on the Bacillus subtilis ATCC13952 to be removed. A decrease in positive charges near the surface of the Bacillus subtilis ATCC13952 might also have 
Table 6. Percentage of arsenic (III) adsorbed in optimization process.

\begin{tabular}{cccc}
\hline \multirow{2}{*}{$\begin{array}{c}\text { arsenic }(\mathrm{III}) \\
\text { conc. }(\mathrm{mg} / \mathrm{L})\end{array}$} & Experiment I & Experiment III & Experiment III \\
\cline { 2 - 4 } 20.0 & 19.033 & \% Removed & \% Removed \\
\hline 40.0 & 38.994 & 18.869 & 17.686 \\
60.0 & 58.972 & 36.335 & 36.240 \\
80.0 & 45.657 & 58.596 & 58.101 \\
100.0 & 36.849 & 45.326 & 46.274 \\
\hline
\end{tabular}

Table 7. Effect of $\mathrm{pH}$ on optimization for arsenic (III) adsorption.

\begin{tabular}{ccccccc}
\hline \multirow{2}{*}{$\mathrm{pH}$} & \multicolumn{2}{c}{ Experiment I } & \multicolumn{2}{c}{ Experiment II } & \multicolumn{2}{c}{ Experiment III } \\
\cline { 2 - 7 } & $C_{e}$ & $Q_{e}$ & $C_{e}$ & $Q_{e}$ & $C_{e}$ & $Q_{e}$ \\
\hline 2.0 & 4.9981 & 5.0019 & 5.0224 & 4.9776 & 4.8993 & 5.1007 \\
4.0 & 3.5008 & 6.4992 & 4.1361 & 5.8639 & 3.7436 & 6.2564 \\
6.0 & 1.0936 & 8.9064 & 1.1432 & 8.8568 & 1.0987 & 8.9013 \\
8.0 & 0.1528 & 9.8472 & 0.2024 & 9.7976 & 0.2337 & 9.7663 \\
10.0 & 0.6698 & 9.3302 & 0.7066 & 9.2934 & 0.6782 & 9.3218 \\
\hline
\end{tabular}

resulted in increased attraction of the arsenic (III) to the nucleophilic groups on the surface of the Bacillus subtilis ATCC13952. The observed decrease in the quantity of arsenic (III) removed at $\mathrm{pH}$ above 8 might due to possible precipitation of arsenic either as calcium arsenate or ferric arsenate than been removed by the Bacillus subtilis ATCC13952. Possible surface membrane deterioration of the Bacillus subtilis ATCC13952 at $\mathrm{pH}$ above 8 might have also contributed to the reduction seen in the capacity of the Bacillus subtilis ATCC13952 to remove the arsenic.

The percentage of arsenic (III) removed increased rapidly from $50.01 \%-98.47 \%$ as seen in Experiment I, 49.77\% - 97.97\% as seen in Experiment II and 51.00\% 97.66\% as seen in Experiment III when pH increased from 2 - 8 (Table 8). The rapid increase in the amount of arsenic removed might have resulted due to accessibility of the available active adsorption sites on the Bacillus subtilis ATCC13952 by the arsenic. A decreased in the amount of protons which could have competed with arsenic for the active adsorption sites might also explain the arsenic removal trend observed. When the $\mathrm{pH}$ was increased from $8-10$, the percentage of arsenic (III) removed decreased from $98.47 \%-93.30 \%$ as seen in Experiment I, 97.97\% - 92.93\% as seen in Experiment II and 97.66\% - 93.21\% as seen in Experiment III. This means that the capacity of the Bacillus subtilis ATCC13952 to remove arsenic (III) decreased with an increase in $\mathrm{pH}$ beyond 8 and might have resulted from a decreased in the affinity of some nucleophiles on the Bacillus subtilis ATCC13952 necessary for arsenic removal.

In the temperature optimization, when temperature was increased from $25^{\circ} \mathrm{C}$ 
- $35^{\circ} \mathrm{C}$, the amount of arsenic (III) removed by $3.0 \mathrm{~mL}\left(2.83 \times 10^{-18} \mathrm{~g}\right)$ of the $\mathrm{Ba}$ cillus subtilis ATCC13952 increased from $7.06-9.90 \mathrm{mg} / \mathrm{L}$ as seen in Experiment I, $7.10-9.89 \mathrm{mg} / \mathrm{L}$ as seen in Experiment II and $7.02-9.90 \mathrm{mg} / \mathrm{L}$ as seen in Experiment III (Table 9). Further increase in temperature from $35^{\circ} \mathrm{C}-45^{\circ} \mathrm{C}$ resulted in a decrease in the amount of arsenic (III) removed from $9.90-9.29$ $\mathrm{mg} / \mathrm{L}$ as seen in Experiment I, 9.89 - $9.30 \mathrm{mg} / \mathrm{L}$ as seen in Experiment II and 9.90 - $9.25 \mathrm{mg} / \mathrm{L}$ as seen in Experiment III. The capacity of Bacillus subtilis ATCC13952 to remove arsenic (III) decreased at high temperature and might have resulted due to cell membrane deterioration. This might have caused some adsorbed arsenic (III) to break away and re-enter the aqueous phase hence the decrease in the amount of arsenic (III) removed.

The percentage of arsenic (III) removed in the temperature optimization increased from 70.69\% - 99.07\% as seen in Experiment I, 71.00\% - 98.97\% as seen in Experiment II and $70.22 \%-99.00 \%$ as seen in Experiment III for temperature ranging from $25^{\circ} \mathrm{C}-35^{\circ} \mathrm{C}$ (Table 10). Further increase in temperature from $35^{\circ} \mathrm{C}-45^{\circ} \mathrm{C}$ resulted in a substantial decrease in the percentage removed from 99.07\% - 92.99\%, 98.97\% - 93.00\% and 99.00\% - 92.57\% as seen in Experiments I, II and III respectively. A decreased in the percentage of arsenic (III) removed at temperature above $35^{\circ} \mathrm{C}$ could be attributed to the deterioration of surface nucleophilic groups of Bacillus subtilis ATCC13952 by high temperature. The deterioration might have led to the destruction of the active adsorption sites on the surfaces of Bacillus subtilis ATCC13952 where arsenic (III) removal was expected to occur.

Table 8. Percentage of arsenic (III) removed in $\mathrm{pH}$ optimization.

\begin{tabular}{cccc}
\hline $\mathrm{pH}$ & Experiment I & Experiment II & Experiment III \\
\cline { 2 - 4 } & \% Removed & \% Removed & \% Removed \\
\hline 2.0 & 50.019 & 49.776 & 51.007 \\
4.0 & 64.992 & 58.639 & 62.564 \\
6.0 & 89.064 & 88.568 & 89.013 \\
8.0 & 98.472 & 97.976 & 97.663 \\
10.0 & 93.302 & 92.934 & 93.218 \\
\hline
\end{tabular}

Table 9. Temperature effect on arsenic (III) adsorption.

\begin{tabular}{cccccccc}
\hline \multirow{2}{*}{$\begin{array}{c}\text { Temperature } \\
{ }^{\circ} \mathrm{C}\end{array}$} & $(\mathrm{K})$ & \multicolumn{2}{c}{ Experiment I } & \multicolumn{2}{c}{ Experiment II } & \multicolumn{2}{c}{ Experiment III } \\
\cline { 3 - 8 } & & $C_{e}$ & $Q_{e}$ & $C_{e}$ & $Q_{e}$ & $C_{e}$ & $Q_{e}$ \\
\hline 25.0 & $(298)$ & 2.9301 & 7.0699 & 2.8994 & 7.1006 & 2.9773 & 7.0227 \\
30.0 & $(303)$ & 1.5987 & 8.4013 & 2.1637 & 7.8363 & 1.6313 & 8.3687 \\
35.0 & $(308)$ & 0.0924 & 9.9076 & 0.1022 & 9.8978 & 0.0997 & 9.9003 \\
40.0 & $(313)$ & 0.1068 & 9.8932 & 0.1134 & 9.8866 & 0.1094 & 9.8906 \\
45.0 & $(318)$ & 0.7004 & 9.2996 & 0.6999 & 9.3001 & 0.7421 & 9.2579 \\
\hline
\end{tabular}


Table 10. Percentage of arsenic removed in temperature optimization.

\begin{tabular}{ccccc}
\hline $\begin{array}{c}\text { Temperature } \\
{ }^{\circ} \mathrm{C}\end{array}$ & $(\mathrm{K})$ & Experiment I & Experiment II & Experiment III \\
\cline { 3 - 5 } 25.0 & $(298)$ & 70.699 & \% Removed & \% Removed \\
30.0 & $(303)$ & 84.013 & 71.006 & 70.227 \\
35.0 & $(308)$ & 99.076 & 78.363 & 83.687 \\
40.0 & $(313)$ & 98.932 & 98.978 & 99.003 \\
45.0 & $(318)$ & 92.996 & 98.866 & 98.906 \\
\hline
\end{tabular}

\subsection{Langmuir Isotherm Parameter Determination for Amount of Arsenic (III) Removed}

The results (Table 11) represent the nonlinear modeling of Langmuir adsorption isotherm for arsenic (III) adsorbed at room temperature $\left(29^{\circ} \mathrm{C}\right)$ with $1.0 \mathrm{~mL}$ $\left(1.90 \times 10^{-21} \mathrm{~g}\right)$ of Bacillus subtilis ATCC13952. The maximum monolayer adsorption capacity $\left(Q_{m}\right)$ of Bacillus subtilis ATCC13952 was estimated as 7.09 $\mathrm{mg} / \mathrm{g}$. The Langmuir constant $K_{L}$ which represents the affinity of Bacillus subtilis ATCC13952 for the arsenic [48] was estimated as $437,753 \mathrm{~L} / \mathrm{g}$. This large value implies that the arsenic (III) got attached to the nucleophilic groups on Bacillus subtilis ATCC13952 by a strong chemical bond.

The large Langmuir constant also shows that Bacillus subtilis ATCC13952 is a potential biosorbent for arsenic in arsenic contaminated aqueous systems. The Langmuir separation factor, $R_{L}$ which shows the feasibility of using Bacillus subtilis ATCC13952 as an adsorbent for arsenic [49] [50] [51] was found to be 2.28 $\times 10^{-7}\left(R_{L} \ll 1\right)$. The small magnitude of the separation factor, $R_{L}$ shows that the arsenic (III) removal by Bacillus subtilis ATCC13952 is a favourable process. The order of the separation factor, $R_{L}$ further shows that arsenic (III) separated easily from the aqueous phase, migrated to Bacillus subtilis ATCC13952 and got bonded to the surface nucleophilic groups. The $R_{L}$ compares favourably with that reported in a similar study [52] [53]. The sum of the normalized errors which is a criterion for selecting the best fit isotherm model [43] [52] was determined to be 1.15 .

\subsubsection{Freundlich Isotherm Parameter Determination for Arsenic Removal}

The Freundlich exponent $1 / n$ (Table 12) which offers insight into the nature of the adsorption process [43] [54] was estimated to be 0.5. This fell in the $0.2-0.8$ range which suggests that the arsenic (III) removal by Bacillus subtilis ATCC13952 is a favourable process which occurred through chemical attachment of the arsenic to the nucleophilic groups of Bacillus subtilis ATCC13952 [55] [56]. The Freundlich constant $K_{f}$ which determines the affinity of Bacillus subtilis ATCC13952 for arsenic [43] [54] was estimated to be $2.99 \mathrm{~L} / \mathrm{g}$ and compared favourably with literature [43] [54] [55] [57] [58] [59] [60]. 
Table 11. Result of Langmuir isotherm parameters for arsenic (III).

\begin{tabular}{lcc}
\hline \multicolumn{3}{c}{$Q_{m}(\mathrm{mg} / \mathrm{mL})=7.0983, K_{L}(\mathrm{~L} / \mathrm{mg})=437,753$, Sep. Factor $=2.28 \mathrm{E}-07, R^{2}=0.968$} \\
\hline Error type & Raw Error Score & Normalized Standard Error \\
\hline STD.ER. & 3.3923 & $5.90 \mathrm{E}-02$ \\
RMSE & $1.52 \mathrm{E}+00$ & $2.64 \mathrm{E}-02$ \\
CHI SQ. & $1.16 \mathrm{E}+00$ & $2.01 \mathrm{E}-02$ \\
EABS & $8.93 \mathrm{E}-04$ & $1.55 \mathrm{E}-05$ \\
ARE & $1.80 \mathrm{E}-05$ & $3.12 \mathrm{E}-07$ \\
HYBRID & $1.16 \mathrm{E}+00$ & $2.01 \mathrm{E}-02$ \\
MPSD & 1.3410 & $2.33 \mathrm{E}-02$ \\
APE & $2.56 \mathrm{E}-04$ & $4.46 \mathrm{E}-06$ \\
G & $1.79 \mathrm{E}-03$ & $3.10 \mathrm{E}-05$ \\
ERRSQ & $5.75 \mathrm{E}+01$ & $1.00 \mathrm{E}+00$ \\
Sum of the normalized standard errors & $1.15 \mathrm{E}+00$ \\
\hline
\end{tabular}

Table 12. Result of Freundlich isotherm parameters for arsenic (III).

\begin{tabular}{ccc}
\hline \multicolumn{3}{c}{ Freundlich isotherm parameters } \\
\hline Error type & Raw Error Score & Normalized Standard Error \\
\hline STD.ER. & 6.7542 & $2.96 \mathrm{E}-02$ \\
RMSE & $3.02 \mathrm{E}+00$ & $1.32 \mathrm{E}-02$ \\
CHI SQ. & $4.59 \mathrm{E}+00$ & $2.01 \mathrm{E}-02$ \\
EABS & $1.77 \mathrm{E}+01$ & $7.77 \mathrm{E}-02$ \\
ARE & 0.3569 & $7.77 \mathrm{E}-02$ \\
HYBRID & $4.59 \mathrm{E}+00$ & $2.01 \mathrm{E}-02$ \\
MPSD & $4.59 \mathrm{E}+00$ & $2.01 \mathrm{E}-02$ \\
APE & 5.0990 & $2.24 \mathrm{E}-02$ \\
G & $4.39 \mathrm{E}+01$ & $1.92 \mathrm{E}-01$ \\
ERRSQ & $2.28 \mathrm{E}+02$ & $1.00 \mathrm{E}+00$ \\
Sum of the normalized standard errors & $1.40 \mathrm{E}+00$ \\
\hline
\end{tabular}

The magnitude of the Freundlich affinity constant $K_{f}$ shows that arsenic (III) removal by Bacillus subtilis ATCC13952 is a possible process and the organism could be used as a potential biosorbent for arsenic in aqueous systems. The sum of the normalized standard errors (Table 12) was determined to be 1.40. This value is relatively large when compared with that estimated for the Langmuir model. Hence, Freundlich isotherm did not offer a better fit to the arsenic (III) adsorption data as compared with the Langmuir isotherm equation. 


\subsubsection{The Temkin Isotherm Parameter Determination for Arsenic (III) Removed}

The Temkin constant $K_{\tau}$ (Table 13) which is the maximum binding energy of arsenic (III) to Bacillus subtilis ATCC13952 [61] [62] [63] was estimated to be 2982.29 L/g. The large binding energy implies that Bacillus subtilis ATCC13952 have substantial affinity for the arsenic (III).

The Temkin constant $b_{r}$, which is the heat of adsorption [26] [63] was found to be $1070.75 \mathrm{~kJ} / \mathrm{mol}$. The large heat of adsorption suggests that arsenic (III) got attached to the nucleophilic groups on Bacillus subtilis ATCC13952 through a feasibly chemical bond formation. The sum of the normalized errors was estimated to be 1.33. Though the Temkin isotherm failed to fit the data when compared with the Langmuir isotherm, it offered a somewhat better fit to the data than the Freundlich isotherm.

\subsubsection{The Dubinin-Radushkevich Isotherm Parameters for Arsenic Removed}

The Dubinin-Radushkevich (D-R) isotherm parameters (Table 14) show the error distribution that minimizes the error between the experimental data and $\mathrm{D}-\mathrm{R}$ isotherm predictions for arsenic (III). The maximum D-R monolayer capacity $Q_{\max }$ capacity of Bacillus subtilis ATCC13952 was determined to be 1.0 $\mathrm{mg} / \mathrm{mL}$. The adsorption energy, $B_{D}$ which determines the nature of the arsenic (III) - Bacillus subtilis ATCC13952 interaction [26] [64] [65] was $138.23 \mathrm{~kJ} \cdot \mathrm{mol}^{-1}$. This fell outside the $8-16 \mathrm{~kJ} / \mathrm{mol}$ range associated with physical adsorption process [26]. The energy per adsorbate was estimated to be $0.06 \mathrm{~kJ} \cdot \mathrm{mol}^{-1}$. This shows that arsenic (III) migrated with a mean energy of $0.06 \mathrm{~kJ} / \mathrm{mol}$ to the surface of Bacillus subtilis ATCC13952 to be removed. The large adsorption energy,

Table 13. Result of Temkin isotherm parameters for arsenic (III) removed.

\begin{tabular}{ccc}
\hline \multicolumn{3}{c}{ Temkin isotherm parameters } \\
$K_{T}(\mathrm{~L} / \mathrm{g})=2982.29, b_{T}(\mathrm{~J} / \mathrm{mol})=1070.75, R^{2}=0.947$, Temp. $302 \mathrm{~K}$, Gas const. $\left(8.314 \mathrm{~J} \cdot \mathrm{mol}^{-1} \cdot \mathrm{K}^{-1}\right)$ \\
\hline Error type & Raw Error Score & Normalized Standard Error \\
\hline STD.ER. & 4.3798 & $4.57 \mathrm{E}-02$ \\
RMSE & 4.3798 & $4.57 \mathrm{E}-02$ \\
CHI SQ. & $1.93 \mathrm{E}+00$ & $2.01 \mathrm{E}-02$ \\
EABS & $5.02 \mathrm{E}+00$ & $5.23 \mathrm{E}-02$ \\
ARE & 0.1010 & $1.05 \mathrm{E}-03$ \\
HYBRID & $1.93 \mathrm{E}+00$ & $2.01 \mathrm{E}-02$ \\
MPSD & $1.93 \mathrm{E}+00$ & $2.01 \mathrm{E}-02$ \\
APE & 1.4433 & $1.50 \mathrm{E}-02$ \\
$\mathrm{G}^{2}$ & $1.06 \mathrm{E}+01$ & $1.10 \mathrm{E}-01$ \\
ERRSQ & $9.59 \mathrm{E}+01$ & $1.00 \mathrm{E}+00$ \\
& Sum of normalized standard errors $1.33 \mathrm{E}+00$ &
\end{tabular}


Table 14. Result of D-R isotherm parameters for arsenic (III) removed.

\begin{tabular}{ccc}
\hline \multicolumn{3}{c}{$\begin{array}{c}\text { Dubinin-Radushkevich (D-R) isotherm parameters } \\
Q_{m}=1.0, B_{D}=138.233, R^{2}=0.877, \text { Temp. } 302 \mathrm{~K}, \mathrm{Gas} \text { const }\left(8.314 \mathrm{~J} \cdot \mathrm{mol}^{-1} \cdot \mathrm{K}^{-1}\right) \\
\text { Energy per adsorbate }\left(\mathrm{kJ} \cdot \mathrm{mol}^{-1}\right)=0.0601\end{array}$} \\
\hline Error type & Raw Error Score & $2.53 \mathrm{E}-02$ \\
\hline STD.ER. & 5.6388 & $3.00 \mathrm{E}-02$ \\
RMSE & 6.6719 & $2.01 \mathrm{E}-02$ \\
CHI SQ. & 4.48 & $1.32 \mathrm{E}-01$ \\
EABS & $2.94 \mathrm{E}+01$ & $2.66 \mathrm{E}-03$ \\
ARE & 0.5911 & $2.01 \mathrm{E}-02$ \\
HYBRID & $4.48 \mathrm{E}+00$ & $2.01 \mathrm{E}-02$ \\
MPSD & $4.48 \mathrm{E}+00$ & $3.79 \mathrm{E}-02$ \\
APE & 8.4448 & $3.79 \mathrm{E}-02$ \\
G & $8.89 \mathrm{E}+01$ & $1.00 \mathrm{E}+00$ \\
ERRSQ & $8.77 \mathrm{E}-01$ & $1.69 \mathrm{E}+00$ \\
\hline
\end{tabular}

$B_{D}$ reaffirms the chemical nature of the arsenic (III) attachment to Bacillus subtilis ATCC13952. The sum of the normalized errors of 1.69 suggests that the D-R isotherm does not provide a better fit to the experimental data when compared with that estimated for the Langmuir isotherm.

\subsubsection{The Toth Isotherm Parameters for Arsenic (III) Removed}

From the Toth isotherm study of the arsenic (III) - Bacillus subtilis ATCC13952 adsorption data (Table 15 ), the maximum monolayer capacity $\left(Q_{t}\right)$ was found to be $1.0 \mathrm{mg} / \mathrm{mL}$ of Bacillus subtilis ATCC13952. This compares favourably with that predicted by the Dubinin-Radushkevich isotherm. The Toth constant $\left(K_{t}\right)$ which relates to the adsorption constant for the arsenic (III) - Bacillus subtilis ATCC13952 system [64] [65] [66] was determined to be $1293.43 \mathrm{~L} / \mathrm{g}$. The large Toth constant $K_{t}$ suggests that Bacillus subtilis ATCC13952 has affinity for arsenic (III) and the removal process was through chemical attachment of arsenic (III) to the surface of Bacillus subtilis ATCC13952. Bacillus subtilis ATCC13952 thus appears to be a possible biosorbent for arsenic in an aqueous system. The Toth exponent $(t)$ was found to be 1 indicating that the Toth isotherm is not reduced to the Langmuir adsorption isotherm under the experimental condition. This might have explained the reason the sum of the normalized standard errors (1.19) determined for the Toth was close to the 1.15 estimated for the Langmuir isotherm and corresponded to similar observations in literature [67] [68] [69] [70] [71]. Though the Toth isotherm modelling reaffirms the existence of significant adsorption sites on the surface of Bacillus subtilis ATCC13952, their energies appear to exhibit a Quasi-Gaussian distribution. Majority of the adsorption sites thus have energy below the mean surface energy as demonstrated by 
Table 15. Result of Toth isotherm parameters for arsenic (III) removed.

\begin{tabular}{ccc}
\hline \multicolumn{3}{c}{ Toth isotherm parameters } \\
\hline Error type & $K_{t}=1293.4399, Q_{t}=1, t=1, a_{t}=7.1000 R^{2}=0.968$ \\
\hline STD.ER. & Raw Error Score & Normalized Standard Error \\
RMSE & 3.7968 & $6.58 \mathrm{E}-02$ \\
CHI SQ. & $1.16 \mathrm{E}+00$ & $5.89 \mathrm{E}-02$ \\
EABS & $1.70 \mathrm{E}-02$ & $2.01 \mathrm{E}-02$ \\
ARE & $3.43 \mathrm{E}-04$ & $2.96 \mathrm{E}-04$ \\
HYBRID & $3.43 \mathrm{E}-04$ & $5.95 \mathrm{E}-06$ \\
MPSD & $1.16 \mathrm{E}+00$ & $2.01 \mathrm{E}-02$ \\
APE & $4.90 \mathrm{E}-03$ & $2.01 \mathrm{E}-02$ \\
G & $3.41 \mathrm{E}-02$ & $8.50 \mathrm{E}-05$ \\
ERRSQ & $5.77 \mathrm{E}+01$ & $5.91 \mathrm{E}-04$ \\
& Sum of the normalized standard error $1.19 \mathrm{E}+00$ & $1.00 \mathrm{E}+00$ \\
\hline
\end{tabular}

the Toth exponent $(t)$ value of 1 . Thus, some heterogeneity existed on the surface of Bacillus subtilis ATCC13952 and that might have led to the inability of the Toth isotherm to better fit the adsorption data as observed in similar studies [29] [54] [66] [70] [71] [72] [73].

\subsubsection{The Sips Isotherm Parameters for Arsenic (III) Removed}

The Sips isotherm assessment (Table 16) shows the Sips maximum monolayer capacity (Qs) to be $1.10 \mathrm{mg} / \mathrm{g}$ of Bacillus subtilis ATCC13952. This maximum monolayer capacity corresponded with the $1.0 \mathrm{mg} / \mathrm{ml}$ of Bacillus subtilis ATCC13952 predicted by both the D-R and the Toth isotherms. However, this maximum monolayer capacity was below the $7.09 \mathrm{mg} / \mathrm{g}$ of Bacillus subtilis ATCC13952 predicted by the Langmuir isotherm model. The Sips constant $\left(K_{s}\right)$ which is related to the affinity of an adsorbent for an adsorbate [67] [74] [75] was found to be $1.05 \mathrm{~L} / \mathrm{g}$ of Bacillus subtilis ATCC13952. The Sips constant $\left(K_{s}>\right.$ $0.5 \mathrm{~L} / \mathrm{g}$ ) indicates that Bacillus subtilis ATCC13952 have affinity for arsenic (III) and the arsenic removal process was through chemisorption as have reported in similar studies [67] [74] [75]. The Sips isotherm could not offer a better fit to the adsorption data due to the relatively large sum of the normalized standard errors (1.90) compared with the 1.15 estimated for the Langmuir isotherm. The Sips exponent $(1 / n)$ was less than 1 (Table 16) predicting that arsenic (III) removal occurred on a heterogeneous surface. This prediction was reversed to that made by the Langmuir isotherm. Hence, the inability of the Sips isotherm equation to better fit the adsorption data might partly due to the homogenous adsorption sites on Bacillus subtilis ATCC13952 as demonstrated by the Langmuir 
Table 16. Result of Sips isotherm parameters for arsenic (III) removed.

\begin{tabular}{ccc}
\hline \multicolumn{3}{c}{ Sips isotherm parameters } \\
\hline Error type & Raw Error Score & Normalized Standard Error \\
\hline STD.ER. & 10.0260 & $2.49 \mathrm{E}-02$ \\
RMSE & 8.9675 & $2.49 \mathrm{E}-02$ \\
CHI SQ. & $8.09 \mathrm{E}+00$ & $2.01 \mathrm{E}-02$ \\
EABS & $4.60 \mathrm{E}+01$ & $1.14 \mathrm{E}-01$ \\
ARE & $9.24 \mathrm{E}-01$ & $2.30 \mathrm{E}-03$ \\
HYBRID & $8.09 \mathrm{E}+00$ & $2.01 \mathrm{E}-02$ \\
MPSD & $8.09 \mathrm{E}+00$ & $2.01 \mathrm{E}-02$ \\
APE & 13.213 & $3.29 \mathrm{E}-02$ \\
G & $2.57 \mathrm{E}+02$ & $6.40 \mathrm{E}-01$ \\
ERRSQ & $4.02 \mathrm{E}+02$ & $1.00 \mathrm{E}+00$ \\
Sum of the normalized standard errors & $1.90 \mathrm{E}+00$ \\
\hline
\end{tabular}

isotherm. The possible Quasi-Gaussian distribution of the energy of the adsorption sites as indicated by the Sips exponent of less than 1 could also account for the deviation of the Sips isotherm to fit the data as has been observed in similar studies [43].

\subsubsection{The Redlich-Peterson (R-P) Isotherm Parameter for Arsenic (III) Removed}

The Redlich-Peterson (R-P) isotherm has the ability to fit adsorption data over lower and higher range of adsorbate concentrations [69] [75] [76] [77]. The R-P isotherm combines the Langmuir and the Freundlich isotherms into one equation and has been found to fit biosorption data well [78] [79]. The results of the R-P isotherm applied to arsenic (III) adsorption data (Table 17). The R-P adsorption constant $\left(K_{R P}\right)$ was $46.67 \mathrm{~L} / \mathrm{g}$. The size of this constant $(>10 \mathrm{~L} / \mathrm{g})$ shows that the arsenic (III) removal by Bacillus subtilis ATCC13952 is feasible and occurred by a chemical attachment of the arsenic (III) to the nucleophilic groups on Bacillus subtilis ATCC13952. The R-P constant, $A_{R P}$ was 3.65 indicating that Bacillus subtilis ATCC13952 has significant affinity for the arsenic (III). The magnitude of the adsorption and the affinity constants show that Bacillus subtilis ATCC13952 appears to have the potential of a biosorbent for arsenic in aqueous systems. The sum of the normalized standard error was 1.63 (Table 17). This suggests that under the experimental condition of this study, the R-P isotherm could not be reduced to the Langmuir isotherm as indicated by $\beta$ greater than unity. The R-P isotherm thus, cannot offer a better fit to the adsorption data when compared with the Langmuir isotherm which had the least sum of the 
Table 17. Result of Redlich-Peterson isotherm parameters for arsenic (III) removed.

\begin{tabular}{ccc}
\hline \multicolumn{3}{c}{ Redlich-Peterson isotherm parameters } \\
\hline Error type & $A_{R P}=3.6599, K_{R P}=46.6792, \beta=1.6975, R^{2}=0.996$ \\
\hline STD.ER. & Raw Error Score & Normalized Standard Error \\
RMSE & 1.3404 & 0.187 \\
CHI SQ. & 1.1989 & 0.167 \\
EABS & 0.145 & 0.0201 \\
ARE & 0.462 & 0.0643 \\
HYBRID & 0.0093 & 0.00129 \\
MPSD & 0.145 & 0.0201 \\
APE & 0.145 & 0.0201 \\
G & 0.132 & 0.0185 \\
ERRSQ & 0.921 & 0.128 \\
& 7.19 & 1 \\
\hline
\end{tabular}

normalized standard errors of 1.15. The inability of the R-P isotherm to fit the data could be attributed to the homogeneity of the surface of Bacillus subtilis ATCC13952 as predicted by the Langmuir isotherm equation. The possible Quasi-Gaussian distribution of the energies of the adsorption sites might have also led to the inability of the isotherm to fit the data.

\subsubsection{Kinetics of Arsenic Removal Process}

The adsorption data of arsenic (III) - Bacillus subtilis ATCC13952 system were subjected to kinetic studies in order to determine the effectiveness of the adsorption process and to understand the mechanism(s) that were involved in the removal of arsenic (III) by Bacillus subtilis ATCC13952. The pseudo-first-order kinetic, pseudo-second order kinetic and the Elovich kinetic models which are widely studied and easily understood kinetic models for heavy metals adsorption were used. The Elovich kinetic model was used to determine the rate of arsenic (III) uptake by Bacillus subtilis ATCC13952 in the kinetic studies and as a tool to confirm the nature of the adsorption process. The results (Tables 18-20) show the parameters of the pseudo-first-order kinetic, pseudo-second-order kinetic and the Elovich kinetic models for the arsenic (III) - Bacillus subtilis ATCC13952. The pseudo-first-order kinetic and the pseudo-second-order kinetic equations [29] [71] [80] are expressed in Equations (19) and (20) respectively as:

$$
\begin{gathered}
Q_{t}=Q_{e}\left(1-\mathrm{e}^{-K_{1} t}\right) \\
Q_{t}=K_{2} Q_{e}
\end{gathered}
$$

where $Q_{t}$ and $Q_{e}$ are the amount of arsenic (III) removed at time $t$ and equilibrium time respectively, $t$ is the optimum adsorption time, and $K_{1}$ and $K_{2}$ are the 
pseudo-first-order and pseudo-second-order kinetic constants respectively. The results (Table 18, Table 19) were obtained from the nonlinear form of the pseudo-first-order and the pseudo-second-order kinetic models. The errors associated with the two kinetic models are those that provided a global minimum of the errors in the kinetic of the arsenic (III) - B. subtilis ATCC13952 adsorption system.

Table 18. Results of pseudo-first-order kinetic parameters for arsenic removed.

Pseudo-first-order kinetic model parameters

\begin{tabular}{|c|c|c|}
\hline \multicolumn{3}{|c|}{ Pseudo-first-order kinetic model parameters } \\
\hline Error type & Raw Error Score & Normalized Standard Error \\
\hline STD.ER. & 1.82 & 0.015 \\
\hline RMSE & 4.46 & 0.037 \\
\hline CHI SQ. & 3.14 & 0.026 \\
\hline EABS & 11.70 & 0.098 \\
\hline ARE & 0.23 & 0.0019 \\
\hline HYBRID & 2.40 & 0.0201 \\
\hline MPSD & 0.05 & 0.000464 \\
\hline APE & 3.36 & 0.0282 \\
\hline $\mathrm{G}^{2}$ & 26.60 & 0.224 \\
\hline ERRSQ & 119.00 & 1.00 \\
\hline & ed standard error & 1.45 \\
\hline
\end{tabular}

Table 19. Results of pseudo-second-order kinetic parameters for arsenic (III).

\begin{tabular}{lcc}
\hline \multicolumn{3}{c}{ Pseudo-second-order kinetic model parameters } \\
$Q_{e}=10.9 \mathrm{mg} / \mathrm{g}^{-1} \cdot \mathrm{day}^{-1}$, Pseudo $2^{\text {nd }}$ order kinetic constant $K_{2}=0.1156 \mathrm{mg} / \mathrm{min}^{-1}, R^{2}=0.996$ \\
\hline Error type & Raw Error Score & Normalized Standard Error \\
\hline STD.ER. & 0.424 & 0.0655 \\
RMSE & 1.04 & 0.160 \\
CHI SQ. & 0.137 & 0.0211 \\
EABS & 2.23 & 0.345 \\
ARE & 0.0449 & 0.00693 \\
HYBRID & 0.130 & 0.0201 \\
MPSD & 0.00202 & 0.000312 \\
APE & 0.642 & 0.0990 \\
G & 4.57 & 0.705 \\
ERRSQ & 6.48 & 1.00 \\
& Sum of normalized standard error & 1.71
\end{tabular}


Table 20. Results of Elovich kinetic parameters for arsenic (III).

\begin{tabular}{ccc}
\hline \multicolumn{3}{c}{ Elovich kinetic model parameters } \\
$\alpha=1 \mathrm{mg} / \mathrm{min}, \beta=1.1919 \mathrm{KJ} / \mathrm{mol}, R^{2}=0.998$ \\
\hline Error type & Raw Error Score & Normalized Standard Error \\
\hline STD.ER. & 1.27 & 0.0315 \\
RMSE & 2.84 & 0.0705 \\
CHI SQ. & 0.791 & 0.0196 \\
EABS & 1.21 & 0.0300 \\
ARE & 0.0243 & 0.000603 \\
HYBRID & 0.810 & 0.0201 \\
MPSD & 0.000590 & 0.0000147 \\
APE & 0.346 & 0.0593 \\
G & 2.38 & 0.00862 \\
ERRSQ & 40.2 & 1.00 \\
& Sum of normalized standard error & 1.24 \\
\hline
\end{tabular}

The pseudo-first-order kinetic had the sum of the normalized errors associated with it to be 1.45 , the rate constant $K_{1}$ was $8.28 \mathrm{mg} / \mathrm{min}$ and the adsorption rate was $4.42 \mathrm{mg} / \mathrm{g} \cdot \mathrm{day}^{-1}$ (Table 18 ) at the $95 \%$ confidence limit. The pseudo-second-order kinetic had the sum of normalized errors associated with it to be 1.71 , the rate constant $K_{2}$ was $10.9 \mathrm{mg} / \mathrm{g} \mathrm{day}^{-1}$ and the adsorption rate was $0.11 \mathrm{mg} / \mathrm{min}$ (Table 19). The sum of the normalized errors associated with the pseudo-first-order kinetic was small as compared with that of the pseudo-second-order kinetic. This indicates that the pseudo-first-order kinetic offered the best fit to the arsenic (III) removal kinetics at the 95\% confidence limit.

\subsubsection{The Elovich Kinetic as a Tool for Reaffirming the Nature and the Kinetics of the Process}

The arsenic (III) - Bacillus subtilis ATCC13952 adsorption data were further subjected to an advanced kinetic investigations using Equation (21) to reaffirm the nature and the kinetics of the adsorption process. The Elovich kinetic equation is expressed as:

$$
Q_{t}=\ln (\alpha \beta) / \beta+\ln t / \beta
$$

where $\alpha$ is the initial rate of arsenic (III) removal and $\beta$ is the minimum surface energy of Bacillus subtilis ATCC13952 as reported elsewhere [81].

The sum of the normalized standard errors, the initial rate of arsenic (III) removal [82] and the minimum surface energy ( $\beta$ ) of Bacillus subtilis ATCC13952 required for the process were found to be $1.29,1.0 \mathrm{mg} / \mathrm{min}$ and $1.19 \mathrm{KJ} / \mathrm{mol} \mathrm{re}-$ spectively (Table 20). While the pseudo-first-order kinetics appears to fit the data than the pseudo-second-order kinetics, assessment of the three kinetic models shows that the Elovich kinetic model provided a good fit to the adsorption data compared with the pseudo-first-order kinetics due to the smaller sum 
of the normalized standard errors associated with it. The capacity of the Elovich kinetic equation to fit the data reaffirms that the arsenic (III) removal occurred via chemisorption. The sums of the normalized errors associated with kinetic models were in the order: pseudo-second-order kinetic (1.71) > pseudo-firstorder kinetic (1.45) > Elovich kinetic model (1.24). The order in which the models fitted the arsenic (III) - Bacillus subtilis ATCC13952 adsorption data compared favourably with that reported in similar studies [62] [66] [81] [83] [84].

\subsubsection{Mechanism of Arsenic Removal by B. subtilis ATCC13952}

The mechanism involving in the arsenic (III) removal by Bacillus subtilis ATCC13952 was investigated with equation 22. The intraparticle diffusion model [85] and the Boyd kinetic model [86] were adopted. The intraparticle diffusion model is based on the theory that the fraction of arsenic (III) removed depends on the membrane diffusivity of Bacillus subtilis ATCC13952 and the radius of arsenic (III) [85] [87]. The intraparticle diffusion model is expressed as:

$$
Q_{t}=K_{i d} t^{0.5}+C
$$

where $K_{i d}$ is the intraparticle diffusion rate constant which is determined from the gradient of the plot of $Q_{t}$ versus $t^{0.5}, C$ is the thickness of the boundary layer which is determined from the intercept, $Q_{t}$ is the quantity of arsenic (III) removed at time $t$ [85] [86] [87] [88]. For an adsorption process that has intraparticle diffusion to be the rate determining step, the plot of $Q_{t}$ versus $t^{0.5}$ generates a straight line through the origin [85] [86] [87] [88]. However, the plot of $Q_{t}$ versus $t^{0.5}$ (Figure 1 ) generated a straight line that deviated from the origin. This indicates existence of a boundary layer suggesting that the removal process was not controlled by intraparticle diffusion alone but other mechanisms were involved [87] [89]. The intercept offer information on the thickness of the boundary layer and the role of the other mechanisms involved in the adsorption process as reported [86] [87] [88] [90] [91] [92] [93]. The intercept suggested that mass transfer processes played key role during the initial phase of the arsenic (III) uptake by Bacillus subtilis ATCC13952 and was followed by an intraparticle diffusion mechanism in the final stage of the process [94]. The intercept further suggested the extent to which the other mechanism(s) involved contributed to the removal process as reported elsewhere [86] [87] [88] [90] [91] [92].

\subsubsection{The Boyd's Diagnostic Plot for Determining the Slowest Step in the Arsenic Removal Process}

The Boyd's kinetic model was used as an analytical tool to determine the slowest step involved in the arsenic removal by Bacillus subtilis ATCC13952. The adsorption data were analyzed with the Boyd's kinetic model [86] [87] expressed as:

$$
B_{t}=-0.498-\ln (1-F)
$$

where $F$ is the fraction of arsenic (III) removed at time $t(\mathrm{~min})$ and $B_{t}$ is a mathematical function of $F$. The fraction $\mathrm{F}$ was determined using the expression: 


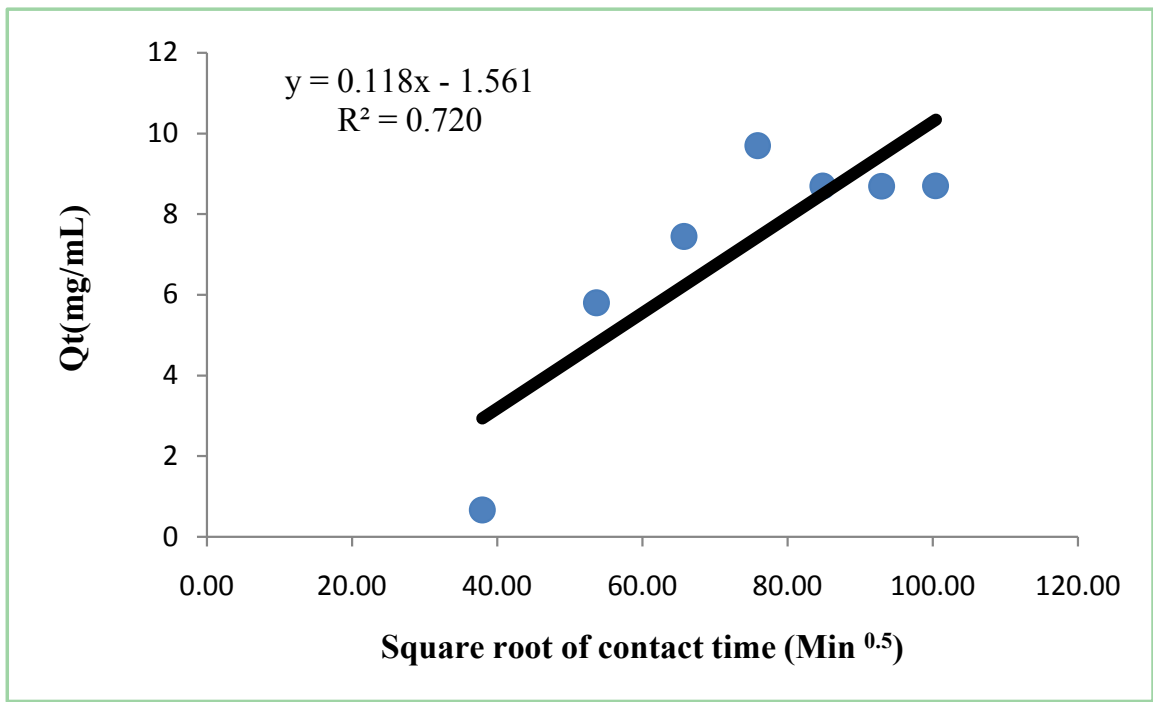

Figure 1. A plot of intraparticle diffusion kinetic for arsenic removal.

$$
F=Q_{t} / Q_{o}
$$

where $Q_{o}$ is the initial concentration of arsenic (III) and $Q_{t}$ is the amount of arsenic (III) removed at time $t$. The Boyd's diagnostic plot (Figure 2) generated an intercept suggesting that the slowest step in the removal process is an external mass transfer process (bulk diffusion) which involved separation of arsenic from solution and subsequent migration to Bacillus subtilis ATCC13952 to be removed as reported in similar studies [86] [87] [89] [95]. Hence, the mechanism of arsenic adsorption by Bacillus subtilis ATCC13952 was found to involve the following steps: 1) Bulk diffusion where arsenic (III) separated from the bulk solution and migrated to the surface of Bacillus subtilis ATCC13952 for attachment. 2) Film diffusion where arsenic (III) diffused across the solution-Bacillus subtilis ATCC13952 interface (boundary layer) into the pores on the surface of Bacillus subtilis ATCC13952. 3) Intraparticle diffusion (pore diffusion) where the arsenic (III) got transported from the surface of Bacillus subtilis ATCC13952 to its interior pores and finally. (4) The attachment of the arsenic (III) to the active adsorption sites on the interior surface of Bacillus subtilis ATCC13952 through chemisorption.

\subsubsection{Thermodynamic Parameters Determination for Arsenic- B. subtilis ATCC13952 System}

The thermodynamic properties of the arsenic (III) - Bacillus subtilis ATCC13952 were studied at temperatures of 298, 303, 308, 313, and $318 \mathrm{~K}$. The study was conducted at the optimum $\mathrm{pH} 8$ with $100 \mathrm{~mL}$ of $10 \mathrm{mg} / \mathrm{mL}$ arsenic (III) solution and $3.0 \mathrm{~mL}\left(2.83 \times 10^{-18} \mathrm{~g}\right)$ of Bacillus subtilis ATCC13952. The rationale of the thermodynamic study was to estimate the thermodynamic properties for a continuous flow water treatment facility that would integrate Bacillus subtilis ATCC13952 into its operation to remove arsenic. The standard Gibb's free energy change $\Delta G^{\circ}(\mathrm{KJ} / \mathrm{mol})$ was estimated using expression: 


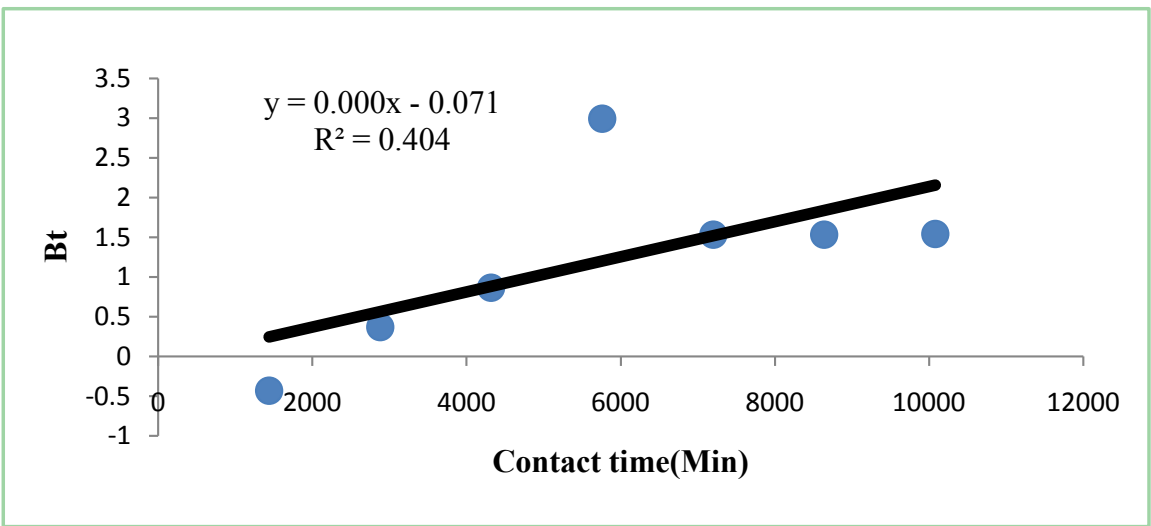

Figure 2. Boyd's diagnostic kinetic model plot of arsenic.

$$
\Delta G^{\circ}=\Delta H^{\circ}-T \Delta S^{\circ}
$$

The standard enthalpy change $\Delta H^{\circ}(\mathrm{KJ} / \mathrm{mol})$ and the standard entropy change $\Delta S^{\circ}(\mathrm{KJ} / \mathrm{mol})$ were estimated from the gradient and the intercept respectively of the Van't Hoff thermodynamic plot (Figure 3). The plot was obtained from the expression:

$$
\ln K_{c}=\Delta S^{\circ} / R-\Delta H^{\circ} / R T
$$

where $K_{c}$ is the equilibrium constant, $T$ is the absolute temperature $(\mathrm{K})$ and $R$ is the universal gas constant $\left(8.314 \mathrm{~J} / \mathrm{mol}^{-1} \cdot \mathrm{K}^{-1}\right)$.

The $\Delta H^{\circ}(\mathrm{kJ} / \mathrm{mol})$ and $\Delta S^{\circ}(\mathrm{KJ} / \mathrm{mol})$ estimated from the Van't Hoff plot were $-159.05 \mathrm{~kJ} / \mathrm{mol}$ and $535.42 \mathrm{~kJ} / \mathrm{mol}$ respectively whilst the $\Delta G^{\circ}(\mathrm{kJ} / \mathrm{mol})$ estimated using Equation (25) was $-159.59 \mathrm{~kJ} / \mathrm{mol}$. The negative $\Delta H^{\circ}$ suggests that the arsenic (III) removal by Bacillus subtilis ATCC13952 is exothermic in nature. This further reaffirms that attachment of the arsenic (III) to the nucleophilic surface groups of Bacillus subtilis ATCC13952 proceeded through a chemical bond and resulted in the loss of large amount of energy (>80 kJ/mol). Negative $\Delta H^{\circ}$ had also been reported in similar studies [64] [93] [96] [97]. The positive $\Delta S^{\circ}$ estimated shows increase randomness at the arsenic (III)-Bacillus subtilis ATCC13952 interface during the initial stage of the arsenic (III) uptake. The $\Delta S^{\circ}$ was comparable to that reported in other studies [56] [95] [98] [99] [100] [101]. The nature of the $\Delta S^{\circ}$ might have resulted from the high affinity of Bacillus subtilis ATCC13952 for the arsenic as predicted by the adsorption isotherms used in the study. Hence, Bacillus subtilis ATCC13952 has the potential to remove arsenic from aqueous systems. The negative $\Delta G^{\circ}$ indicates that the arsenic (III) removal by Bacillus subtilis ATCC13952 is a spontaneous and thermodynamically feasible process.

\subsubsection{Minimum Energy Requirement of the Arsenic-B. subtilis ATCC13952 System}

The data obtained from the arsenic (III) - Bacillus subtilis ATCC13952 adsorption system were investigated for its minimum energy requirement to initiate the removal process. The minimum energy was estimated by optimization of nonlinear 


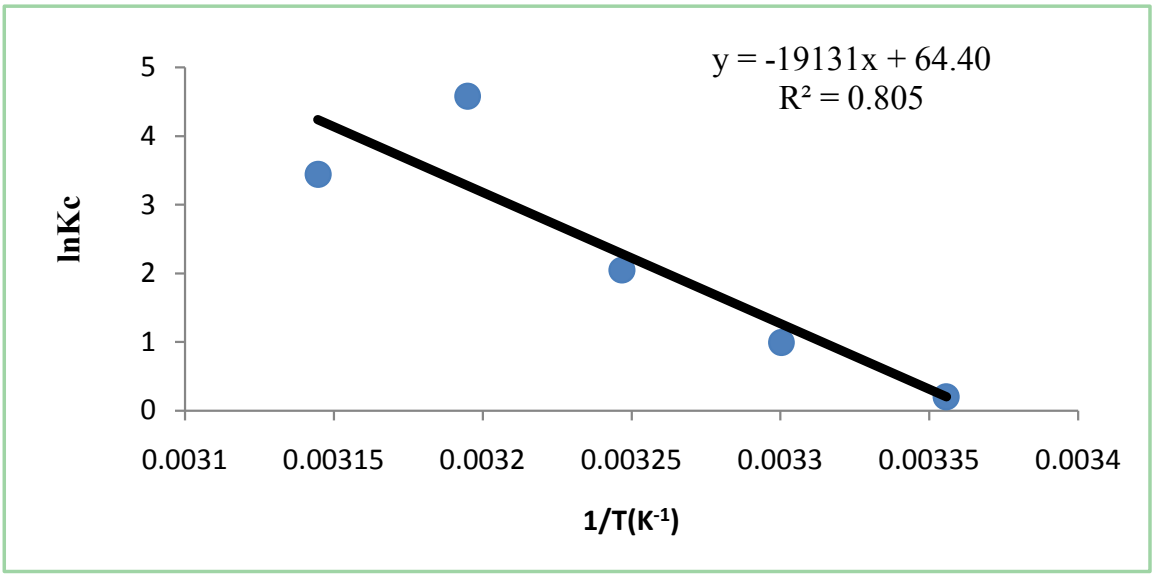

Figure 3. Van't Hoff thermodynamic plot for arsenic (III).

the form of the Arrhenius energy equation expressed in Equation (27) via the generalized reduced gradient algorithms of the solver add-in of MS excel 2007 spread sheet.

$$
K=A \mathrm{e}^{-E a / R T}
$$

where $E a$ is the minimum energy $\left(\mathrm{kJ} \cdot \mathrm{mol}^{-1}\right), R$ is the gas constant $(8.314$ $\left.\mathrm{J} \cdot \mathrm{mol}^{-1} \cdot \mathrm{K}^{-1}\right), T$ is the absolute temperature $(\mathrm{K})$ and $A$ is the pre exponential factor which is constant for the arsenic (III) - B. subtilis ATCC13952 system over the temperature range studied [102] [103]. The quantity of arsenic (III) removed under the optimum conditions of $\mathrm{pH} 8$, contact time of 4 days, temperature range of $25^{\circ} \mathrm{C}-45^{\circ} \mathrm{C} ; 3.0 \mathrm{~mL}$ of Bacillus subtilis ATCC13952 and $100 \mathrm{~mL}$ of 10 $\mathrm{mg} / \mathrm{mL}$ arsenic (III) were used to estimate the minimum energy requirement. The minimum energy needed by the arsenic (III) - Bacillus subtilis ATCC13952 system to initiate arsenic (III) removal process was found to be $1.0 \mathrm{~kJ} / \mathrm{mol}$.

\subsubsection{Application of the Developed Method on Community Groundwater Samples}

The mean total arsenic in the community groundwater samples (Table 21) after samples were treated using the optimum conditions of 4 days contact time, 3.0 $\mathrm{mL}$ of Bacillus subtilis ATCC13952, $\mathrm{pH} 8$ and $35^{\circ} \mathrm{C}$ showed a remarkable reduction in the arsenic concentration. Bacillus subtilis ATCC13952 exhibited substantial capacity to remove arsenic from the groundwater samples and the percentage arsenic removed was similar to that removed in the optimization process. The capacity of Bacillus subtilis ATCC13952 to remove arsenic is due to the large adsorption energy and the high affinity of the organism for the arsenic as has been confirmed by the adsorption isotherms used in this study. The quantity of arsenic removed ranged from $99.96 \%-99.97 \%, 99.96 \%-99.98 \%$ and $99.96 \%$ 99.97\% for Ackon, Tamso and Odumasi respectively. The mean total arsenic concentration after treatment ranged from $0.0113 \pm 0.0011 \mu \mathrm{g} / \mathrm{L}$ to $0.0148 \pm$ $0.0001 \mu \mathrm{g} / \mathrm{L}$ across all sample points and was below the $10 \mu \mathrm{g} / \mathrm{L}$ permitted by the World Health Organization. 
Table 21. Mean arsenic levels in groundwater samples at Ackon $(\mu \mathrm{g} / \mathrm{L})$.

\begin{tabular}{|c|c|c|c|}
\hline Sample & $\begin{array}{c}\text { Levels before } \\
\text { treatment }\end{array}$ & $\begin{array}{c}\text { Levels after } \\
\text { treatment }\end{array}$ & \% Removed \\
\hline W1 & $47.2555 \pm 1.7547$ & $0.01417 \pm 0.0005$ & 99.969 \\
\hline W2 & $64.4483 \pm 1.3821$ & $0.0128 \pm 0.0002$ & 99.979 \\
\hline $\mathrm{BH}$ & $32.1572 \pm 4.5833$ & $0.0115 \pm 0.0005$ & 99.963 \\
\hline \multicolumn{4}{|c|}{ Mean arsenic levels in groundwater samples at Tamso $(\mu \mathrm{g} / \mathrm{L})$. } \\
\hline Sample & $\begin{array}{l}\text { Levels before } \\
\text { treatment }\end{array}$ & $\begin{array}{c}\text { Levels after } \\
\text { treatment }\end{array}$ & \% Removed \\
\hline W1 & $71.4583 \pm 1.4679$ & $0.0142 \pm 0.0002$ & 99.979 \\
\hline W2 & $74.4533 \pm 0.8324$ & $0.0148 \pm 0.0001$ & 99.980 \\
\hline $\mathrm{BH}$ & $47.7722 \pm 0.8547$ & $0.0146 \pm 0.0002$ & 99.969 \\
\hline \multicolumn{4}{|c|}{ Mean arsenic levels in groundwater samples at Odumasi $(\mu \mathrm{g} / \mathrm{L})$. } \\
\hline Sample & $\begin{array}{c}\text { Levels before } \\
\text { treatment }\end{array}$ & $\begin{array}{c}\text { Levels after } \\
\text { treatment }\end{array}$ & \% Removed \\
\hline W1 & $37.065 \pm 1.6528$ & $0.0113 \pm 0.0011$ & 99.969 \\
\hline W2 & $39.270 \pm 0.7837$ & $0.0122 \pm 0.0019$ & 99.968 \\
\hline $\mathrm{BH}$ & $32.980 \pm 0.9257$ & $0.0126 \pm 0.0011$ & 99.961 \\
\hline SW & $87.967 \pm 1.2723$ & $0.0256 \pm 0.0003$ & 99.970 \\
\hline
\end{tabular}

W1: Well 1, W2: Well 2, BH: Borehole, SW: Surface Water.

\section{Conclusions}

When the optimum conditions were used on the community groundwater samples, $99.96 \%$ - 99.97\% of arsenic were removed by Bacillus subtilis ATCC13952. Kinetic of the process showed that the arsenic removal proceeded through second order kinetic with rate constant and removal rate of $10.9 \mathrm{mg} / \mathrm{g}^{-1} \%$ day and $0.11 \mathrm{mg} / \mathrm{min}^{-1}$ respectively. The Elovich kinetic model gave the best fit to the experimental data. This implies that the process occurred by chemical attachment of the arsenic to the surface groups of Bacillus subtilis ATCC13952. The removal process was found to be exothermic with $\Delta H^{\circ}$ of $-159.05 \mathrm{KJ} / \mathrm{mol}$. This reaffirmed that the process was chemisorption.

The removal mechanism of Bacillus subtilis ATCC13952 using Boyd's kinetic model was found to involve bulk diffusion, film diffusion, intraparticle diffusion, or pore diffusion, and finally the adsorption of the arsenic at the active sites on the interior surface of Bacillus subtilis ATCC13952. The rate-determining step was found to be bulk diffusion. The Langmuir isotherm gave the best fit to the experimental data. The maximum monolayer capacity of Bacillus subtilis ATCC13952 and its affinity for the arsenic were determined to be $7.09 \mathrm{mg} / \mathrm{g}$ and $437753 \mathrm{~L} / \mathrm{g}$ respectively through nonlinear modeling of the Langmuir isotherm. 
The large affinity constant also reaffirmed that the adsorption process was chemisorption. The Langmuir separation factor $\left(R_{L}\right)$ and $\Delta G^{\circ}$ were $2.28 \times 10^{-7}$ $\left(R_{L} \ll 1\right)$ and $-159.59 \mathrm{KJ} / \mathrm{mol}$ respectively indicating that the process was favourable, spontaneous and thermodynamically feasible. From the results of this study, it is clear that Bacillus subtilis ATCC13952 is an efficient biosorbent for arsenic in arsenic-contaminated aqueous systems. Hence, Bacillus subtilis ATCC13952 appears to hold the key to purging the environment of arsenic even in cases of severe contamination.

\section{Acknowledgements}

The authors wish to thank the Department of Chemistry Education, College of Agriculture Education, Akenten Appiah-Menka University of Skills Training and Entrepreneurial Development, Mampong-Ashanti, Ghana for providing all the chemicals and equipment for this research. The authors also wish to thank Department of Molecular Biology, School of Biological Sciences, College of Agriculture and Natural Sciences, University of Cape Coast, Cape Coast, Ghana for providing the organism (Bacillus subtilis ATCC13952) for this study.

\section{Conflicts of Interest}

The authors declare no conflicts of interest regarding the publication of this paper.

\section{References}

[1] Bano, Y.J.A.A.S. (2020) The Critical Link between Knowledge Management and Succession Management at Higher Education Institutions.

https://doi.org/10.2139/ssrn.3588158

[2] Danso, F. (2020) Mineral Resource Governance and Human Development in Ghana. Routledge, London. https://doi.org/10.4324/9781003005537

[3] Duncan, A.E. (2020) The Dangerous Couple: Illegal Mining and Water Pollution-A Case Study in Fena River in the Ashanti Region of Ghana. Journal of Chemistry, 2020, Article ID: 2378560. https://doi.org/10.1155/2020/2378560

[4] Antwi-Boateng, O. and Akudugu, M.A. (2020) Golden Migrants: The Rise and Impact of Illegal Chinese Small-Scale Mining in Ghana. Politics \& Policy, 48, 135-167. https://doi.org/10.1111/polp.12342

[5] Worlanyo, A.S. and Li, J.F. (2020) Evaluating the Environmental and Economic Impact of Mining for Post-Mined Land Restoration and Land-Use: A Review. Journal of Environmental Management, 279, Article ID: 111623. https://doi.org/10.1016/j.jenvman.2020.111623

[6] Mantey, J., et al. (2020) Influence of Illegal Artisanal Small-Scale gold Mining Operations (Galamsey) on Oil and Grease (O/G) Concentrations in Three Hotspot Assemblies of Western Region, Ghana. Environmental Pollution, 263, Article ID: 114251. https://doi.org/10.1016/j.envpol.2020.114251

[7] He, X., et al. (2020) Groundwater Arsenic and Fluoride and Associated Arsenicosis and Fluorosis in China: Occurrence, Distribution and Management. Exposure and Health, 12, 355-368. 
[8] Raghu, H.V., Parkunan, T. and Kumar, N. (2020) Application of Nanobiosensors for Food Safety Monitoring. In: Environmental Nanotechnology, Volume 4, Springer, Berlin, 93-129. https://doi.org/10.1007/978-3-030-26668-4_3

[9] Dhaif-Allah, M.A.H., et al. (2020) Kinetic and Isotherm Modeling for Acid Blue 113 Dye Adsorption onto Low-Cost Nutraceutical Industrial Fenugreek Seed Spent. Applied Water Science, 10, 1-16. https://doi.org/10.1007/s13201-020-1141-3

[10] Al-Ghouti, M.A. and Da'ana, D.A. (2020) Guidelines for the Use and Interpretation of Adsorption Isotherm Models: A Review. Journal of Hazardous Materials, 393, Article ID: 122383. https://doi.org/10.1016/j.jhazmat.2020.122383

[11] Gusain, R., Kumar, N. and Ray, S.S. (2020) Recent Advances in Carbon Nanomaterial-Based Adsorbents for Water Purification. Coordination Chemistry Reviews, 405, Article ID: 213111. https://doi.org/10.1016/j.ccr.2019.213111

[12] Ganguly, P., Sarkhel, R. and Das, P. (2020) Synthesis of Pyrolyzed Biochar and Its Application for Dye Removal: Batch, Kinetic and Isotherm with Linear and Non-Linear Mathematical Analysis. Surfaces and Interfaces, 20, Article ID: 100616. https://doi.org/10.1016/j.surfin.2020.100616

[13] Ngeno, E.C., et al. (2019) Caffeine and Ciprofloxacin Adsorption from Water onto Clinoptilolite: Linear Isotherms, Kinetics, Thermodynamic and Mechanistic Studies. South African Journal of Chemistry, 72, 136-142. https://doi.org/10.17159/0379-4350/2019/v72a17

[14] Okpara, O.G., et al. (2020) Optimum Isotherm by Linear and Nonlinear Regression Methods for Lead (II) Ions Adsorption from Aqueous Solutions Using Synthesized Coconut Shell-Activated Carbon (SCSAC). Toxin Reviews, 1-14. https://doi.org/10.1080/15569543.2020.1802596

[15] Umar, A. (2020) Adsorption of Methyl Orange from Aqueous Solution Using Chitin and Polystyrene-Modified Chitin: Kinetics and Isotherm Studies. ChemSearch Journal, 11, 99-109.

[16] Chakraborty, P., et al. (2019) Linearity and Non-Linearity Analysis of Isotherms and Kinetics for Ibuprofen Remotion Using Superheated Steam and Acid Modified Biochar. Process Safety and Environmental Protection, 126, 193-204. https://doi.org/10.1016/j.psep.2019.04.011

[17] Choi, H.Y., et al. (2020) Thiol-Functionalized Cellulose Nanofiber Membranes for the Effective Adsorption of Heavy Metal Ions in Water. Carbohydrate Polymers, 234, Article ID: 115881. https://doi.org/10.1016/j.carbpol.2020.115881

[18] de Luna, M.D.G., et al. (2019) Applicability of Composite Silica-Divinylbenzene in Bioethanol Dehydration: Equilibrium, Kinetic, Thermodynamic, and Regeneration Analysis. Energy \& Fuels, 33, 7347-7356. https://doi.org/10.1021/acs.energyfuels.9b00161

[19] Saigl, Z.M. and Ahmed, A.M. (2020) Separation of Rhodamine B Dye from Aqueous Media Using Natural Pomegranate Peels. Indonesian Journal of Chemistry, 21, 212-224. https://doi.org/10.22146/ijc.58592

[20] Kumar, K.V., et al. (2019) Characterization of the Adsorption Site Energies and Heterogeneous Surfaces of Porous Materials. Journal of Materials Chemistry A, 7, 10104-10137. https://doi.org/10.1039/C9TA00287A

[21] El Fargani, H., et al. (2017) Removal of Anionic Dyes by Silica-Chitosan Composite in Single and Binary Systems: Valorization of Shrimp Co-Product "Crangon-Crangon" and "Pandalus Borealis". Journal of Materials, 8, 724-739.

[22] Ayawei, N., Ebelegi, A.N. and Wankasi, D. (2017) Modelling and Interpretation of adsorption Isotherms. Journal of Chemistry, 2017, Article ID: 3039817. 
https://doi.org/10.1155/2017/3039817

[23] Terangpi, P. (2018) Evaluation of Aniline Formaldehyde Condensate Polymer in Two Different Forms for Heavy Metals and Anionic Dyes Adsorption from Wastewater.

[24] Subbaiah, M.V. and Kim, D.-S. (2016) Adsorption of Methyl Orange from Aqueous Solution by Aminated Pumpkin Seed Powder: Kinetics, Isotherms, and Thermodynamic Studies. Ecotoxicology and Environmental Safety, 128, 109-117. https://doi.org/10.1016/j.ecoenv.2016.02.016

[25] Contreras-Contreras, J.A., et al. (2020) Polyphenols from Sugarcane Vinasses, Quantification, and Removal Using Activated Carbon after Biochemical Treatment in Laboratory-Scale Thermophilic Upflow Anaerobic Sludge Blanket Reactors. Water, Air, \& Soil Pollution, 231, 1-12. https://doi.org/10.1007/s11270-020-04733-5

[26] Amrhar, O., Nassali, H. and Elyoubi, M.S. (2015) Adsorption of a Cationic Dye, Methylene Blue, onto Moroccan Illitic Clay. Journal of Material and Environmental Science, 6, 3054-3065.

[27] Ullah, S., et al. (2020) Synthesis and Characterization of Mesoporous MOF UMCM-1 for $\mathrm{CO} 2 / \mathrm{CH} 4$ Adsorption; an Experimental, Isotherm Modeling and Thermodynamic Study. Microporous and Mesoporous Materials, 294, Article ID: 109844. https://doi.org/10.1016/j.micromeso.2019.109844

[28] Kua, T.L., et al. (2020) Aquatic Plant, Ipomoea Aquatica, as a Potential Low-Cost Adsorbent for the Effective Removal of Toxic Methyl Violet 2B Dye. Applied Water Science, 10, 1-13. https://doi.org/10.1007/s13201-020-01326-9

[29] Otheman, A., Hakima, N. and Mohamed, S.E. (2015) Two and Three-Parameter Isothermal Modeling for Adsorption of Crystal Violet Dye onto Natural Illitic Clay: Nonlinear Regression Analysis. Journal of Chemical and Pharmaceutical Research, 7, 892-903.

[30] Khandelwal, A., et al. (2020) Linear and Nonlinear Isotherm Models and Error Analysis for the Sorption of Kresoxim-Methyl in Agricultural Soils of India. Bulletin of Environmental Contamination and Toxicology, 104, 503-510.

[31] Amini, E. and Ebadian, A. (2020) Numerical Solution and Error Analysis for Linear and Nonlinear Delay Differential Equations. Journal of New Researches in Mathematics, 6, 83-98.

[32] Jasper, E.E., Ajibola, V.O. and Onwuka, J.C. (2020) Nonlinear Regression Analysis of the Sorption of Crystal Violet and Methylene Blue from Aqueous Solutions onto an Agro-Waste Derived Activated Carbon. Applied Water Science, 10, Article No. 132. https://doi.org/10.1007/s13201-020-01218-y

[33] Outram, J.G., et al. (2020) Application of Non-Linear Regression Analysis and Statistical Testing to Equilibrium Isotherms: Building an Excel Template and Interpretation. Separation and Purification Technology, 258, Article ID: 118005. https://doi.org/10.1016/j.seppur.2020.118005

[34] Alkurdi, S.S.A., et al. (2020) Inorganic Arsenic Species Removal from Water Using Bone Char: A Detailed Study on Adsorption Kinetic and Isotherm Models Using Error Functions Analysis. Journal of Hazardous Materials, 405, Article ID: 124112. https://doi.org/10.1016/j.jhazmat.2020.124112

[35] Benmessaoud, A., et al. (2020) A Comparative Study of the Linear and Non-Linear Methods for Determination of the Optimum Equilibrium Isotherm for Adsorption of $\mathrm{Pb}^{2+}$ Ions onto Algerian Treated Clay. Iranian Journal Chemical Engineering Research, 39, 74-82.

[36] Paluri, P., Ahmad, K.A. and Durbha, K.S. (2020) Importance of Estimation of Op- 
timum Isotherm Model Parameters for Adsorption of Methylene Blue onto Biomass Derived Activated Carbons: Comparison between Linear and Non-Linear Methods. Biomass Conversion and Biorefinery, 1-18. https://doi.org/10.1007/s13399-020-00867-y

[37] Hashem, A., et al. (2020) Adsorption of $\mathrm{Pb}$ (II) Ions from Contaminated Water by 1,2,3,4-Butanetetracarboxylic Acid-Modified Microcrystalline Cellulose: Isotherms, Kinetics, and Thermodynamic Studies. International Journal of Biological Macromolecules, 164, 3193-3203. https://doi.org/10.1016/j.ijbiomac.2020.08.159

[38] de Oliveira, P.V., et al. (2020) Adsorption of $17 \beta$-Estradiol in Graphene Oxide through the Competing Methanol Co-Solvent: Experimental and Computational Analysis. Journal of Molecular Liquids, Article ID: 114738. https://doi.org/10.1016/j.molliq.2020.114738

[39] Lobo-Recio, M.Á., et al. (2020) Highly Efficient Removal of Aluminum, Iron, and Manganese IONS Using Linde Type-A Zeolite Obtained from Hazardous Waste. Chemosphere, 267, Article ID: 128919.

https://doi.org/10.1016/j.chemosphere.2020.128919

[40] Abbas, M. (2020) Modeling of Adsorption Isotherms of Heavy Metals onto Apricot Stone Activated Carbon: Two-Parameter Models and Equations Allowing Determination of Thermodynamic Parameters. Materials Today. Proceedings, 43, 33593364. https://doi.org/10.1016/j.matpr.2020.05.320

[41] Holmquist, B., Sjöström, A. and Nasrin, S. (2020) Approximating Noncentral ChiSquared to the Moments and Distribution of the Likelihood Ratio Statistic for Multinomial Goodness of Fit. In: Recent Developments in Multivariate and Random Matrix Analysis, Springer, Berlin, 175-198.

https://doi.org/10.1007/978-3-030-56773-6_11

[42] Oyetade, O.A., et al. (2017) Experimental and DFT Studies on the Selective Adsorption of $\mathrm{Pb}^{2+}$ and $\mathrm{Zn}^{2+}$ from Aqueous Solution by Nitrogen-Functionalized Multiwalled Carbon Nanotubes. Separation and Purification Technology, 188, 174-187. https://doi.org/10.1016/j.seppur.2017.07.022

[43] Hadi, M., Mckay, G. and Mohamed, R.S. (2010) Equilibrium Two Parameter Isotherms of Acid Dyes Sorption by Activated Carbons: Study of Residual Errors. Journal of Chemical Engineering, 160, 408-416.

https://doi.org/10.1016/j.cej.2010.03.016

[44] Aniagor, C.O. and Menkiti, M.C. (2020) Relational Description of an Adsorption System Based on Isotherm, Adsorption Density, Adsorption Potential, Hopping Number and Surface Coverage. Sigma: Journal of Engineering \& Natural Sciences/ Mühendislik ve Fen Bilimleri Dergisi, 38, 1073-1098.

[45] Anderson, R., Biong, A. and Gómez-Gualdrón, D.A. (2020) Adsorption Isotherm Predictions for Multiple Molecules in MOFs Using the Same Deep Learning Model. Journal of Chemical Theory and Computation, 16, 1271-1283. https://doi.org/10.1021/acs.jctc.9b00940

[46] Piccin, J.S., et al. (2017) Adsorption Isotherms in Liquid Phase: Experimental, Modeling, and Interpretations. In: Adsorption Processes for Water Treatment and Purification, Springer, Berlin, 19-51. https://doi.org/10.1007/978-3-319-58136-1_2

[47] Ghosh, S., et al. (2020) Molecular and Taxonomic Characterization of Arsenic (As) Transforming Bacillus sp. Strain IIIJ3-1 Isolated from As-Contaminated Groundwater of Brahmaputra River Basin, India. BMC Microbiology, 20, 256.

https://doi.org/10.1186/s12866-020-01893-6

[48] Nthunya, L.N. (2016) Electrospun Antibacterial Cyclodextrin and Chitosan Based 
Nanocomposite Filtration Materials for Use in Drinking Water Purification.

[49] Ayalew, M. (2020) Removal of Arsenic from Paint Industries Waste Water by Chemically Modified Low Cost Adsorbent Derived from Sugarcane Bagasse. https://doi.org/10.29294/IJASE.6.3.2020.1390-1398

[50] Asare, E.A., et al. (2018) Utilization of Bacillus thuringiensis MC28 as a Biosorbent for Mercury in Groundwaters from Some Selected Gold Mining Communities in the Wassa West District of the Western Region of Ghana. Environmental Nanotechnology, Monitoring \& Management, 9, 95-106. https://doi.org/10.1016/j.enmm.2017.12.005

[51] Manjula, S., et al. (2019) Molecular Identification of Gut Microflora of Bacillus coagulans Supplemented Feed Fed Macrobrachium rosenbergii Post-Larvae Using 16S rRNA. The International Journal of Biotechnology, 8, 19-37. https://doi.org/10.18488/journal.57.2019.81.19.37

[52] Subramanyam, B. and Das, A. (2009) Linearized and Non-Linearized Isotherm Models Comparative Study on Adsorption of Aqueous Phenol Solution in Soil. Internal Journal of Environmental Science Technology, 6, 633-640. https://doi.org/10.1007/BF03326104

[53] Ruiz, C.G. (2006) Mercury(II) Removal from Aqueous Solutions by Nonviable Bacillus sp. from a Tropical Estuary. Bioresource Technology, 97, 1907-1911. https://doi.org/10.1016/j.biortech.2005.08.014

[54] Mohamed, E., et al. (2015) Isotherm, Kinetic and Thermodynamic Studies for the Sorption of Mercury(II) onto Activated Carbon from Rosmarinus officinalis Leaves. American Journal of Analytical Chemistry, 6, 1-10. https://doi.org/10.4236/ajac.2015.61001

[55] Gandhi, N., et al. (2012) Adsorption Studies of Fluoride on Multani Matti and Red Soil. Research Journal of Chemical Sciences, 2, 2-37.

[56] Stephen, I. and Sulochana, N. (2002) Basic Lead Adsorption on a Low Cost Carbonaceous Sorbent, Kinetic and Equilibrium Studies. Indian Journal of Chemical Technology, 9, 201-208.

[57] Mehdi, M.S. and Behnamfard, A. (2011) Modeling of Equilibrium Data for Free Cyanide Adsorption onto Activated Carbon by Linear and Non-Linear Regression Methods. International Conference on Environment and Industrial Innovation, 12, 79-84.

[58] Shen, X., et al. (2009) Kinetics and Thermodynamics of Sorption of Nitroaromatic Compounds to As-Grown and Oxidized Multiwalled Carbon Nanotubes. Journal of Colloid and Interface Science, 330, 1-8. https://doi.org/10.1016/j.jcis.2008.10.023

[59] Alagumuthu, G. and Rajan, M. (2010) Kinetic and Equilibrium Studies on Fluoride Removal by Zirconium(IV)-Impregnanted Ground Nutshell Carbon. Hemijska Industrija, 64, 295-304. https://doi.org/10.2298/HEMIND100307017A

[60] Nuhuglu, Y. and Oguz, A. (2003) Removal of Copper(II) from Aqueous Solution by Biosorption on the Cone Biomass of Thuja orientalis. Process Biochemistry, 38, 627-1631. https://doi.org/10.1016/S0032-9592(03)00055-4

[61] Hoong, C.K., et al. (2011) Biosorption Parameter Estimation with Genetic Algorithm. Water, 3, 177-195. https://doi.org/10.3390/w3010177

[62] Hameed, B.H., Mahmoud, D.K. and Ahmad, A.L. (2008) Equilibrium Modeling and Kinetic Studies on the Adsorption of Basic Dye by a Low-Cost Adsorbent: Coconut (Cocos nucifera) Bunch Waste. Journal of Hazardous Materials, 158, 65-72. https://doi.org/10.1016/j.jhazmat.2008.01.034 
[63] Igwe, J.C., Abia, A.A. and Sonde, C.U. (2011) Pseudo Kinetics and Intraparticle Diffusion Models for Sorption of $\mathrm{Zn}(\mathrm{II}), \mathrm{Cd}(\mathrm{II})$ and $\mathrm{Pb}(\mathrm{II})$ Ions onto Maize Cob. ABSU Journal of Environment, Science and Technology, 1, 25-36.

[64] Zheng, H., et al. (2008) Equilibrium, Kinetic and Thermodynamic Studies on the Sorption of 4-Hydroxyphenol on Cr-Bentonite. Journal of Chemical Engineering, 143, 117-123. https://doi.org/10.1016/j.cej.2007.12.022

[65] Saltali, K., Sarı, A. and Aydın, M. (2007) Removal of Ammonium Ion from Aqueous Solution by Natural Turkish (Yıldizeli) Zeolite for Environmental Quality. Journal of Hazardous Materials, 141, 258-263. https://doi.org/10.1016/j.jhazmat.2006.06.124

[66] Foo, K.Y. and Hameed, B.H. (2010) Insights into the Modeling of Adsorption Isotherm Systems. Journal of Chemical Engineering, 156, 2-10.

https://doi.org/10.1016/j.cej.2009.09.013

[67] Febriantoa, J., et al. (2009) Equilibrium and Kinetic Studies in Adsorption of Heavy Metals Using Biosorbent: A Summary of Recent Studies. Journal of Hazardous Materials, 162, 616-645. https://doi.org/10.1016/j.jhazmat.2008.06.042

[68] Apiratikul, R. and Pavasant, P. (2008) Batch and Column Studies of Biosorption of Heavy Metals by Caulerpa lentillifera. Bioresource Technology, 99, 2766-2777. https://doi.org/10.1016/j.biortech.2007.06.036

[69] Basha, S., Murthy, Z.V.P. and Jha, B. (2008) Sorption of Hg(II) from Aqueous Solutions onto Carica papaya: Application of Isotherms. Industrial and Engineering Chemistry Research, 47, 980-986. https://doi.org/10.1021/ie071210o

[70] Senthilkumar, R., et al. (2007) Application of Seaweeds for the Removal of Lead from Aqueous Solution. Journal of Biochemical Engineering, 33, 211-216. https://doi.org/10.1016/j.bej.2006.10.020

[71] Vijayaraghavan, K., et al. (2006) Biosorption of Nickel(II) Ions onto Sargassum wightii: Application of Two-Parameter and Three-Parameter Isotherm Models. Journal of Hazardous Materials, 133, 304-308. https://doi.org/10.1016/j.jhazmat.2005.10.016

[72] Hong, Z., et al. (2009) Sorption Isotherm and Kinetic Modeling of Aniline on Cr-Bentonite. Journal of Hazardous Materials, 167, 141-147. https://doi.org/10.1016/j.jhazmat.2008.12.093

[73] İsmail, T. (2012) Ammonium Removal from Aqueous Solutions by Clinoptilolite: Determination of Isotherm and Thermodynamic Parameters and Comparison of Kinetics by the Double Exponential Model and Conventional Kinetic Models. International Journal of Environmental Research of Public Health, 9, 970-984. https://doi.org/10.3390/ijerph9030970

[74] Green, R.C., Rodriguez, T.V. and Gomez, G.B. (2008) Cadmium and Zinc Removal from Aqueous Solutions by Bacillus jeotgali: $\mathrm{pH}$, Salinity and Temperature Effects. Bioresource Technology, 99, 3864-3870. https://doi.org/10.1016/j.biortech.2007.06.047

[75] Ho, Y.A.E. and Ofomaja, B. (2006) Biosorption Thermodynamics of Cadmium on Coconut Copra Meal as Biosorbent. Biochemical Engineering Journal, 30, 117-123. https://doi.org/10.1016/j.bej.2006.02.012

[76] Dursun, A.Y. (2006) A Comparative Study on Determination of the Equilibrium, Kinetic and Thermodynamic Parameters of Biosorption of Copper(II) and Lead(II) Ions onto Pretreated Aspergillus niger. Journal of Biochemical Engineering, 28, 187-195. https://doi.org/10.1016/j.bej.2005.11.003

[77] Padmavathy, V. (2008) Biosorption of Nickel(II) Ions by Baker's Yeast: Kinetic, Thermodynamic and Desorption Studies. Bioresource Technology, 99, 3100-3109. 
https://doi.org/10.1016/j.biortech.2007.05.070

[78] Shroff, K.A. and Vaidya, V.K. (2012) Effect of Pre-Treatments on the Biosorption of Chromium(VI) Ions by Dead Biomass of Rhizopus arrhizus. Journal of Chemical Technology and Biotechnology, 87, 294-304. https://doi.org/10.1002/jctb.2715

[79] Tripathi, M., Mishra, S.S. and Tripathi, V.R. (2011) Predictive Approach for Simultaneous Biosorption of Hexavalent Chromium and Pentachlorophenol Degradation by Bacillus cereus RMLAU1. African Journal of Biotechnology, 10, 6052-6061.

[80] Mohammad, O., Mohammad, S.K. and Almas, Z. (2013) Biosorption of Heavy Metals by Bacillus thuringiensis Strain OSM29 Originating from Industrial Effluent Contaminated North Indian Soil. Saudi Journal of Biological Sciences, 1, 121-129. https://doi.org/10.1016/j.sjbs.2012.11.006

[81] ChinWua, F., Tsengb, R.L. and Juang, R.S. (2009) Characteristics of Elovich Equation Used for the Analysis of Adsorption Kinetics in Dye-Chitosan Systems. Chemical Engineering, 150, 366-373. https://doi.org/10.1016/j.cej.2009.01.014

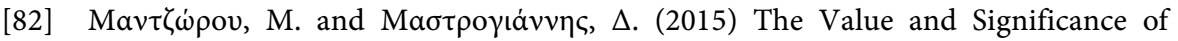
Knowing the Patient for Professional Practice, According to the Carper's Patterns of Knowing.

[83] Ajaelu, C.J.I., Oluwafunke, L.A. and Olafisoye, O.V. (2011) Equilibrium and Kinetic Studies of the Biosorption of Heavy Metal (Cadmium) on Cassia Siamea Bark. American-Eurasian Journal of Scientific Research, 6, 123-130.

[84] Bulgariu, D. and Bulgariu, L. (2012) Equilibrium and Kinetics Studies of Heavy Metal Ions Biosorption on Green Algae Waste Biomass. Bioresource Technology, 103, 489-493. https://doi.org/10.1016/j.biortech.2011.10.016

[85] Parimalam, R., Raj, V. and Sivakumar, P. (2011) Adsorption Isotherms, Kinetics, Thermodynamics and Desorption Studies of Reactive Organge 16 on Activated Carbon Derived from Ananas comosus (L) Carbon. Engineering and Applied Sciences, 6, 15-26.

[86] Okewale, A.O., Babayemi, K.A. and Olalekan, A.P. (2013) Adsorption Isotherms and Kinetics Models of Starchy Adsorbents on Uptake of Water from EthanolWater Systems. International Journal of Applied Science and Technology, 3, 35-42.

[87] Tsibranska, E.H. (2010) Comparison of Different Kinetic Models for the Adsorption of Heavy Metals onto Activated Carbon from Apricot Stones. Belgarian Chemical Communication, 3, 320-371.

[88] Zhou, M., et al. (2007) Kinetic and Equilibrium Studies of $\mathrm{Cr}$ (VI) Biosorption by Dead Bacillus licheniformis Biomass. World Journal of Microbiology and Biotechnology, 23, 43-48. https://doi.org/10.1007/s11274-006-9191-8

[89] Soude, C. (2011) Pseudo-Kinetic and Intraparticle Diffusion Models for Sorption of $\mathrm{Zn}(\mathrm{II}), \mathrm{Cd}(\mathrm{II})$ and $\mathrm{Pb}(\mathrm{II})$ Ions onto Maize Cob. Journal of Environmental Science and Technology, 1, 509-512.

[90] Adriano, O.H., et al. (1998) Control of Cell Shape and Elongation by the Rod A Gene in Bacillus subtilis. Molecular Microbiology, 28, 235-247. https://doi.org/10.1046/j.1365-2958.1998.00766.x

[91] Sukhada, S. and Varsha, K.V. (2016) Elucidation of Sorption Mechanism of R. arrhizus for Reactive Blue 222 Using Equilibrium and Kinetic Studies. Journal of Microbial and Biochemical Technology, 8, 236-246. https://doi.org/10.4172/1948-5948.1000292

[92] Westphal, A.J., et al. (2003) Kinetics of Size Changes of Individual Bacillus thuringiensis Spores in Response to Changes in Relative Humidity. Proceedings of the Na- 
tional Academy of Sciences of the United States of America, 100, 3461-3466. https://doi.org/10.1073/pnas.232710999

[93] Tan, I.A.W. and Hamed, B.H. (2010) Adsorption Isothers, Kinetics, Thermodynamics and Desorption of Activated Carbon Derived from Oil Palm Empty Fruit Bunch. Journal of Applied Science, 10, 2565-2571.

https://doi.org/10.3923/jas.2010.2565.2571

[94] Mohanty, K., et al. (2005) Removal of Cr (VI) from Dilute Aqueous Solution by Activated Carbon Developed from Terminalia arjuna Nuts Activated with $\mathrm{ZnCl}_{2}$. Chemical Engineering Science, 60, 3049-3059.

https://doi.org/10.1016/j.ces.2004.12.049

[95] Nethaji, S., Sivasamy, A. and Mandal, A.B. (2013) Adsorption Isotherms, Kinetics and Mechanism for the Adsorption of Cationic and Anionic Dyes onto Carbonaceous Particles Prepared from Juglans regia Shell Biomass. International Journal of Environmental Science and Technology, 10, 231-242.

https://doi.org/10.1007/s13762-012-0112-0

[96] Azraa, A., et al. (2012) Equilibrium, Kinetic and Thermodynamic Studies on the Adsorption of Direct Dye onto a Novel Green Adsorbent Developed from Uncaria Gambir Extract. Journal of Physical Science, 23, 1-13.

[97] Rounak, M.S. (2011) Thermodynamic Adsorption-Desorption of Metolachlor and 2,4-D on Agricultural Soils. International Journal of Chemistry, 3, 34-146. https://doi.org/10.5539/ijc.v3n4p134

[98] Elouear, Z., et al. (2008) Heavy Metals Removal from Aqueous Solutions by Activated Phosphate Rock. Journal of Hazardous Materials, 156, 412-420. https://doi.org/10.1016/j.jhazmat.2007.12.036

[99] Ilkunur, S. and Hanife, B. (2013) Equilibrium and Kinetic Studies on the Biosorption of 2-Chlorophenol and 4-Chlorophenol by Live Aspergillus niger. Ekoloji, 22, 1-12. https://doi.org/10.5053/ekoloji.2013.881

[100] Mall, I.D., et al. (2005) Adsorptive Removal of Malachite Green Dye from Aqueous Solution by Bagasse Fly Ash and Activated Carbon-Kinetic Study and Equilibrium Isotherm Analyses: Colloids Surface Adsorption. Colloids and Surfaces A: Physicochemical and Engineering Aspects, 264, 17-28. https://doi.org/10.1016/j.colsurfa.2005.03.027

[101] Onal, Y., et al. (2006) Removal of Malachite Green Using Carbon-Based Adsorbent. Journal of Hazardous Materials B, 128, 150-157. https://doi.org/10.1016/j.jhazmat.2005.07.055

[102] Panida, S. and Pisit, C. (2010) Equilibrium Isotherm, Thermodynamic and Kinetic Studies of Lead Adsorption onto Pineapple and Paper Waste Sludges. International Journal of Energy and Environment, 4, 88-97.

[103] Salman, J.M., Al-Saad, K.A. and Abbas, N.A. (2012) Adsorption of 2,4-Dichlorophenoxyacetic Acid onto Data Seeds Activated Carbon: Equilibrium, Kinetic and Thermodynamic Studies. International Journal of Chemical Science, 10, 677-690. 